\title{
Tuberculosis contact investigation in low prevalence countries: a European
}

\section{consensus}

\author{
C.G.M. Erkens*, M. Kamphorst*\#, I. Abubakar`, G.H. Bothamley ${ }^{+}$, D. Chemtob ${ }^{\S}$, \\ W. Haas ${ }^{f}$, G.B. Migliori**, H.L. Rieder ${ }^{\# \#, \uparrow \uparrow, ~ J-P . ~ Z e l l w e g e r ~}{ }^{++}$and C. Lange ${ }^{\S \S, f f}$
}

ABSTRACT: Contact investigation to identify individuals with tuberculosis and latent infection with Mycobacterium tuberculosis is an important component of tuberculosis control in low tuberculosis incidence countries. This document provides evidence-based and best-practice policy recommendations for contact tracing among high- and medium-priority contacts in a variety of settings. It provides a basis for national guidelines on contact investigation and tuberculosis outbreak management, and should support countries and tuberculosis control managers in evaluating and revising national policies. A review of existing guidelines, a literature search, several meetings and consultation with experts were used to formulate and grade recommendations for action during contact investigation.

Available tests to identify individuals with latent infection with $M$. tuberculosis are designed to identify immune response against mycobacterial antigens and have variable predictive value for the likelihood to develop active tuberculosis in different populations. Contact investigation should therefore be limited to situations with a clear likelihood of transmission or to those with a higher probability of developing active tuberculosis, for instance, young children and immunocompromised persons. A risk assessment-based approach is recommended, where the need to screen contacts is prioritised on the basis of the infectiousness of the index case, intensity of exposure and susceptibility of contacts.

KEYWORDS: Active case finding, contact investigation, consensus statement, latent tuberculosis infection, preventive chemotherapy, tuberculosis

$\mathbf{T}$ he primary objective of any tuberculosis control activity is prompt identification and adequate treatment of newly emerging tuberculosis cases. Timely identification and adequate treatment of those with transmissible tuberculosis reduces the risk of exposure of community members. As a result, the future incidence of tuberculosis is diminished, as the prevalence of infection with Mycobacterium tuberculosis declines in the cohort with the passage of time. The Stop TB Strategy and World Health Organization (WHO) guidelines for effective tuberculosis control [1] provide a framework for tackling tuberculosis, largely for countries with a high tuberculosis incidence.
Low-incidence countries in the European region have, in addition, addressed the goal of tuberculosis elimination [2-5], requiring a substantially broader approach. In particular, in addition to case identification among contacts of newly identified potential sources of infection, emphasis is also given to adequate preventive therapy or, as a minimum if the latter is contraindicated, follow-up of persons with recent $M$. tuberculosis infection. Identification of infected contacts thus targets an important subset of the prevalently infected who had escaped the focus on the prevention of infection. Contact investigation is the most readily available intervention to identify recently infected individuals and has been

\section{AFFILIATIONS}

*KNCV Tuberculosis Foundation, The Hague, and

\#Dept of Tuberculosis Control, Municipal Public Health Service Rotterdam-Rijnmond, Rotterdam, the Netherlands.

"Tuberculosis Section, Health Protection Agency Centre for Infections, and ${ }^{+}$North-East London Tuberculosis Network, Homerton University Hospital, London, UK.

${ }^{\text {s}}$ Dept of Tuberculosis \& AIDS, Jerusalem, Israel.

${ }^{f}$ Robert Koch Institute, Berlin,

${ }^{\S \S}$ Research Center Borstel, Borstel, and

ffUniversity of Lübeck, Lübeck, Germany.

**WHO Collaborating Centre for Tuberculosis and Lung Diseases, Fondazione S. Maugeri, Care and Research Institute, Tradate, Italy.

\#\#International Union Against Tuberculosis and Lung Disease, Paris, France.

"Institute of Social and Preventive Medicine, University of Zurich, Zurich, and

${ }^{+}$Swiss Lung Association, Bern, Switzerland.

CORRESPONDENCE

C.G.M. Erkens, KNCV Tuberculosis Foundation, Parkstraat 17, PO Box 146, 2501 CC The Hague, The Netherlands

E-mail: erkensc@kncvtbc.nl

Received:

Dec 232009

Accepted after revision:

March 182010

European Respiratory Journal Print ISSN 0903-1936

Online ISSN 1399-3003 
identified as an essential component of the tuberculosis control and elimination strategy in most low-incidence countries.

Since 1990, WHO, the International Union Against Tuberculosis and Lung Disease (The Union), and the KNCV Tuberculosis Foundation have jointly organised a series of workshops, aimed at reorienting tuberculosis control in the European region of $\mathrm{WHO}$, formulating guidelines and standards to foster consensus on a commonly agreed approach. Consensus building has emphasised wide consultation among tuberculosis control experts, national correspondents of EuroTB, and representatives of ministries of health. These workshops have become known as "Wolfheze Conferences", christened after the location in the Netherlands where the first meetings took place. From these meetings a series of consensus documents, position papers and recommendations has emerged [2, 6-11].

In 2006, a survey was undertaken to determine the contact investigation policies and practices in Europe, the results of which were presented and discussed at the Wolfheze Conference in Vilnius (Lithuania) in September 2006. In addition, a more comprehensive survey of national policies on active case finding across the WHO European region was conducted by the Tuberculosis Network European Trials Group (TBNET) [12]. Both surveys revealed some variation in active case-finding policies and strategies in Europe, although all countries screened close contacts of cases of sputum smear-positive tuberculosis. This suggested both the need and potential usefulness of a common evidence-based policy, both for countries moving towards eliminating tuberculosis, and for those transiting from an intermediate- to lowincidence epidemiology. More importantly, there was no consensus of what constituted a positive tuberculin skin test. A consensus statement should support countries and national tuberculosis control managers in evaluating and, where indicated, revising national policy.

The consensus document presented here aims to serve as a basis for national guidelines on contact investigation and outbreak management in tuberculosis prevention and control/ elimination programmes in the countries of the WHO European Region. It fits with, and specifically supplements, the principles of the framework for an action plan to fight tuberculosis in the European Union from the European Centre for Disease Control (ECDC) [13] and those of the Berlin Declaration on Tuberculosis [14].

\section{METHODS}

A draft consensus document was prepared for discussion at the 2008 Wolfheze Conference by representatives from European low-incidence countries. It took recourse to published guidelines for contact investigations from the USA [15], the UK [16], Canada [17], Germany [18] and the Netherlands [19], and additional material published subsequently through November 2009. The available evidence and recommendations in each section were graded using a letter code in parentheses, in accordance with the Scottish Intercollegiate Guidelines Network (SIGN) grading system advocated by the European Respiratory Society (see Appendix), primarily by the coauthor with responsibility for the concerned section, and finalised in concordance with the first and the senior author.

\section{Definitions}

In this document, "tuberculosis" refers to clinically, bacteriologically, histologically and/or radiologically active disease. "Latent infection with M. tuberculosis" is usually defined as presumptive infection with $M$. tuberculosis complex, as evidenced by a "positive" tuberculin skin test reaction and/ or a positive interferon- $\gamma$ release assay (IGRA), without any sign of clinically or radiologically manifest disease. However, the biological nature of latent infection with $M$. tuberculosis is controversial [20]. Direct identification of individuals who are latently infected with live $M$. tuberculosis, without active tuberculosis, is currently not possible. The tests available in clinical practice to identify individuals with latent $M$. tuberculosis infection, the in vivo tuberculin skin test and the ex vivo IGRA are designed to identify a memory of an adaptive immune response against mycobacterial antigens, rather than to identify true latent infection [21]. The proportion of individuals with a persistently positive immune response against $M$. tuberculosis by tuberculin skin test or IGRA who are truly latently infected with live mycobacteria is unknown. The acronym "LTBI" is commonly used synonymously to describe latent infection with $M$. tuberculosis, and is adapted from the American Thoracic Society (ATS) terminology "latent tuberculosis infection" [22]. It is used pragmatically to describe those individuals with a positive adaptive immune response in the tuberculin skin test or in a M. tuberculosis-specific IGRA, who are potentially infected with $M$. tuberculosis.

\section{GOAL AND OBJECTIVES OF CONTACT INVESTIGATION}

The yield of secondary cases among contacts of newly identified tuberculosis cases is largely determined by source characteristics, the definition of a "contact", and the duration of exposure of contacts to the index (putative source) case. If the net is cast wide, the yield may be infinitesimally small [23]. More typically, if investigations focus on contacts of cases with bacteriologically confirmed tuberculosis of the respiratory tract in settings with a generally well functioning tuberculosis program, such as in the USA, and investigations are conducted according to priority settings, $\sim 1 \%$ of such identified contacts may be expected to be identifiable secondary cases in routine practice [24].

The risk of progression to tuberculosis is highest immediately following a median incubation period of $\sim 6$ weeks that is required for a first-manifest immunological response [25]. The subsequent risk follows an approximately exponential decline during the first $\sim 7$ yrs $[26,27]$. After this period, the incidence levels off and appears to persist for many years or even decades. In placebo recipients in preventive therapy trials in the USA, the incidence of tuberculosis beyond $\sim 7$ yrs following infection was $\sim 1$ per 1,000 person-yrs [26]. This is remarkably identical to the incidence observed in the placebo group in the Bacille Calmette Guérin (BCG) trial in the UK [27]. The early incidence is, importantly, determined by the age at which infection is acquired [28]. It may be as large as $30-40 \%$ among infants, to as low as $2 \%$ among primary school children [29]. Among primary school children who were tuberculin skin test-positive at recruitment into a BCG trial in Puerto Rico, case incidence was as low as 0.8 per 100 person-yrs [30]. However, the applicability of the latter findings to the current situation in Europe from this tropical setting (relative contribution to 
cross-reactions with the tuberculin skin test resulting from prior infection with environmental mycobacteria) with a different epidemiology, remains questionable. Among those who did develop tuberculosis subsequent to infection within the first 7 yrs, $\sim 60 \%$ did so within the first, and cumulatively $80 \%<2$ yrs subsequent to tuberculin skin test conversion in the placebo group in the BCG trial in the UK $[31,32]$. Thus, the lifetime risk of developing active tuberculosis after conversion of the tuberculin skin test is determined by the risk during the first few years, plus the cumulative incidence during the lowincidence period that follows it, which, in turn, is determined by remaining life expectancy. COMSTOCK et al. [30] estimated the lifetime risk of a child (beyond the highest risk period) to be cumulatively 10\%. VYNNYCKY and FINE [33] estimated the age-weighted average for England and Wales (UK) at 12\%, and HorsburGH [28] at 10-20\%. A study from Germany estimated the two-year progression rate to active tuberculosis in healthy contacts with positive IGRA responses to be close to $15 \%$ [34]. Thus, there is a fairly large variation in the estimates for the incidence immediately following infection but much less so for the cumulative lifetime incidence, the explanation for which remains at least partially elusive.

The objectives of contact investigation are as follows: 1) to reduce morbidity and fatality due to tuberculosis by early identification and adequate treatment of contacts with tuberculosis; 2) to arrest further transmission by early detection of possible (secondary) source cases; 3 ) to contribute to the elimination of tuberculosis through prevention of future cases of tuberculosis in the population by detection and preventive therapy of infected contacts at risk of developing tuberculosis.

In some situations, a source case investigation is conducted to identify an infectious person who might be the source case of someone with tuberculosis or latent infection with $M$. tuberculosis [35, 36]. This is usually done when recent transmission is likely as in the following cases: 1) a child aged $<5$ yrs of age is found with tuberculosis or infection with $M$. tuberculosis without a known source of infection; 2) a person with tuberculosis likely due to recent infection with $M$. tuberculosis (primary tuberculosis) is found without a known source of infection; 3) a cluster of persons with tuberculin skin test or IGRA conversion is found in a high-risk institution.

\section{LIKELIHOOD AND RISK OF TRANSMISSION}

\section{Relative infectiousness of index patient and infectious period}

Every tuberculosis patient should be interviewed promptly after diagnosis to assess the need for, and the urgency of, contact investigation. The extent of contact investigation will depend on the degree of infectiousness of the index patient, the period of infectiousness, the putative location(s) of transmission, the likelihood of the contacts to develop tuberculosis if infected, and the proportion of persons found to be infected.

With few exceptions, only patients with tuberculosis of the lung parenchyma or airways transmit tubercle bacilli. In patients with mediastinal or hilar lymphadenopathy due to tuberculosis, in individuals infected with HIV who have low numbers of circulating CD4 T-cells, and in patients with pleural effusions concealing the lung parenchyma, sputum cultures may yield $M$. tuberculosis even when the lung parenchyma on chest radiography appears normal [37]. Anecdotal case reports point to the possibility of aerosolproducing procedures among cases with extrapulmonary tuberculosis resulting in transmission [38-41]. Isolated extrapulmonary tuberculosis does not warrant contact investigations, but any patient with extrapulmonary tuberculosis requires radiological and bacteriological examinations to exclude concomitant pulmonary disease.

The potential of infectiousness is related to the patient's ability to aerosolise bacilli and to the number of bacilli that are aerosolised [42-44]. Any respiratory manoeuvre (talking, singing, coughing, sneezing) produces aerosols. The larger the physical force of the manoeuvre, the larger the number of expelled droplets and the smaller their size; the smaller the size, the quicker they evaporate to droplet nuclei [45-47]. However, the frequency of the event, especially coughing, is of practical relevance for the transmission of $M$. tuberculosis. The number of bacilli contained in expelled droplets is determined by the underlying lesions in the respiratory tract and their access to the airways. The largest number of bacilli is found in cavitary lesions, where they may number in excess of 100 million colony-forming units [48]. If spontaneously produced sputum is positive on direct microscopic examination, even a weak positive result points to a minimum concentration of $5,000-10,000$ bacilli per $\mathrm{mL}$ sputum $[49,50]$. In contrast, more sensitive methods, such as culture, may detect as few as 10-100 bacilli per $\mathrm{mL}$ sputum [51]. The fraction attributable to transmission from sputum smear-negative, culture-positive tuberculosis will vary depending on the disease extent prevalent in the community before the diagnosis is made [52]. For example, in a recent survey, patients with smearnegative, culture-positive tuberculosis have been estimated to be responsible for $13 \%$ of all transmissions resulting in secondary cases in The Netherlands [53]. In industrialised countries, the direct examination of spontaneously produced sputum by microscopy has become the exception, rather than the rule. Instead, sputum is commonly concentrated by centrifugation and, where it cannot be obtained directly, sputum induction, bronchoalveolar lavage or other techniques are employed to obtain a specimen, to increase the sensitivity of diagnosis. Thus, "sputum smear-positive" has attained a substantially different meaning from that used in historical publications. As a result, the fraction of transmissions attributable to culture-only positive patients has reduced for this reason as well. Nevertheless, certain characteristics (table 1) that identify the most potent transmitters still hold. Even where concentration of specimens has become the rule, there are still laboratories which continue to perform direct sputum smear examinations, and they should be encouraged to do so, as this will always assist in rapidly identifying those patients with the highest potential of being transmitters.

Because of the change in the way bacteriological examinations are performed and the relatively increasing contribution to transmission by cases positive by means other than microscopic examination, a pragmatic approach is to define as a potential transmitter of tubercle bacilli any patient in whom acid-fast bacilli have or $M$. tuberculosis has been isolated from a respiratory specimen other than from biopsy alone. 


TABLE 1 Parameters to assess the infectiousness of the
index patient
Anatomical site: pulmonary tuberculosis [54]
The production of sputum [54]
Results of sputum smear examination [55]
Results of sputum culture [55]
Cavitations $[55,56]$
Coughing $[45,57,58]$

\section{Infectious period}

Diagnostic delay (both by the patient and the healthcare system) is an important determinant of the period of infectiousness. There is a substantial body of information on the decline of infectiousness subsequent to treatment initiation [59-61], an observation supported by bacteriological evidence of the early bactericidal activity of antituberculosis medications [62].

In contrast, onset of infectiousness cannot be determined objectively; thus, guidance to estimate the duration of infectiousness prior to diagnosis must be defined pragmatically. Expert opinion commonly uses onset of cough as a proxy measuring point for when transmissibility began. In the absence of cough, the time of onset of any respiratory tract symptom attributable to tuberculosis has been proposed as a substitute to define onset of infectiousness [15].

The number of identified infected contacts naturally raises a question about the duration for which the index case had been infectious. To determine the period of infectiousness during which contacts will have to be identified, the following rules may be used (level of evidence: D; see Appendix) [15]. 1) Pulmonary cases with a positive sputum smear should be considered to have been potentially infectious for the period the patient is known to have been coughing (initially to a maximum of 3 months). The presence of radiologically identifiable cavitations increases the assumed degree of infectiousness. 2) Pulmonary cases with culture-positive pulmonary tuberculosis and two negative sputum smears may be considered potentially infectious for a period of 1 month before the date of tuberculosis diagnosis, where the presence of cough or a cavity increases the assumed degree of infectiousness. 3) A person with drugsusceptible pulmonary tuberculosis should be considered potentially infectious until the person has completed $\geqslant 2$ weeks of appropriate treatment [60] in the absence of any suspicion or proof of multidrug-resistant tuberculosis and has improvement from symptoms [63].

Nevertheless, the "two-week" observation [60] cannot always be taken at face value. Some patients never transmit, while others may do so for a prolonged period of time. Furthermore, and perhaps most importantly, that study [60] was conducted by ascertaining the increment of transmissions among contacts. As a large proportion of susceptible contacts may have been infected prior to initiation of chemotherapy, any subsequent increment may be difficult to ascertain. However, in the context of patients who are hospitalised and are potentially exposing other, more vulnerable persons, it would be dangerous to assume that all infectiousness has ceased in an initially sputum smear-positive patient after just 2 weeks of chemotherapy, as most of these still excrete viable bacilli. Such patients should be discharged as soon as possible to their home environment where little further damage can be safely assumed or if, among patients living in precarious situations, their follow-up can be assured. Should prolonged hospitalisation be required, however, every precaution must be taken to reduce the risk of nosocomial transmission for the prolonged period of time it takes until the cough frequency is diminished and excretion of viable bacilli ceases. In case of drug-resistant tuberculosis, the commonly associated prolongation of infectiousness must be considered. Some hospitals with the necessary infrastructure thus opt for prolonging hospitalisation of such patients in negative-pressure rooms until clear bacteriological and clinical evidence emerges that the potential of transmissibility has been substantially reduced.

\section{Locations of transmission}

Environmental characteristics are key determinants for transmission probability. Outdoors, transmission is highly improbable unless source and susceptible person are in talking distance. Bacillary dispersion is immediate and sunlight or even skyshine exert rapid killing of any viable bacilli [64, 65]. In contrast, indoors, bacilli are potentially trapped, disperse within a room, and may remain viable and suspended in the air for a prolonged period of time [66-69]. Proximity is thus of much lesser importance.

Room size, air (re)circulation and, particularly, ventilation play an overriding role in dispersion of bacilli and dilution of their concentration in the ambient air. Therefore, only specific investigation, preferably including a visit to the putative locations where transmission may have occurred, will provide additional information to estimate the risk of tuberculosis transmission, and may also assist in identifying additional contacts.

\section{Susceptibility of the contacts}

Contacts at highest risk of tuberculosis following infection and who will benefit most from preventive therapy are listed in table 2. Such persons are accorded a higher priority for evaluation. Tuberculin skin test and IGRA may be falsely negative in immunocompromised patients (see Diagnostic tools to evaluate contacts of tuberculosis patients). Young children ( $<2$ yrs of age) have a higher risk of progression to tuberculosis, while children aged $2-4$ yrs have a comparatively low risk for progression of tuberculosis (table 3). However, all children $<5$ yrs of age are at increased risk of meningeal and/ or disseminated tuberculosis compared with adults. As in adults, the majority of disease manifestations in children occur in the first 6-12 months following primary infection. Furthermore, the longer remaining life expectancy adds to a cumulatively larger lifetime risk in children [30]. Therefore, children $<5$ yrs of age are a main target group for contact investigation.

\section{DIAGNOSTIC TOOLS TO EVALUATE CONTACTS OF TUBERCULOSIS PATIENTS}

The diagnosis of tuberculosis requires a high index of suspicion raised by medical history, physical examination, imaging studies and laboratory results for tuberculosis. Laboratory confirmation must always be sought and relies on studying the morphology of micro-organisms (microscopy), culture techniques determining the viability through metabolic 


\begin{tabular}{|c|c|c|c|}
\hline \multirow{2}{*}{$\begin{array}{l}\text { TABLE } 2 \\
\text { Condition }\end{array}$} & \multicolumn{3}{|c|}{$\begin{array}{l}\text { Conditions increasing the risk for progression to } \\
\text { tuberculosis and OR (from retrospective studies) } \\
\text { or relative risk (RR; from prospective studies) }\end{array}$} \\
\hline & & [Ref.] & OR or $\mathbf{R R}$ \\
\hline \multicolumn{4}{|c|}{ Immune suppression } \\
\hline \multicolumn{2}{|c|}{ HIV-positive and tuberculin skin test-positive } & [71-73] & $50-110$ \\
\hline \multicolumn{2}{|c|}{ AIDS } & {$[74,75]$} & $110-170$ \\
\hline \multicolumn{2}{|c|}{ Solid organ transplantation related to } & & $20-74$ \\
\hline \multicolumn{2}{|c|}{ immunosuppressant therapy } & [76-78] & \\
\hline \multicolumn{2}{|c|}{ Receiving anti-TNF- $\alpha$ treatment } & [79-81] & $1.5-17$ \\
\hline \multicolumn{2}{|c|}{$\begin{array}{l}\text { Corticosteroids }>15 \mathrm{mg} \text { prednisolone equivalent } \\
\text { per day for }>2-4 \text { weeks } \#\end{array}$} & {$[82,83]$} & 4.9 \\
\hline \multicolumn{2}{|c|}{ Malignancy } & & $4-8$ \\
\hline \multicolumn{2}{|c|}{ Haematological malignancy (leukemias, lymphomas) } & [84] & 16 \\
\hline \multicolumn{2}{|c|}{ Carcinoma of the head or neck and lung } & {$[85]$} & $2.5-6.3$ \\
\hline \multicolumn{2}{|c|}{ Gastrectomy } & {$[86,87]$} & 2.5 \\
\hline \multicolumn{2}{|c|}{ Jejunoileal bypass } & {$[88,89]$} & $27-63$ \\
\hline \multicolumn{2}{|c|}{ Silicosis } & [90-92] & 30 \\
\hline \multicolumn{2}{|c|}{ Chronic renal failure/haemodialysis } & {$[93,94]$} & $10-25$ \\
\hline \multicolumn{2}{|c|}{ Diabetes mellitus } & [95-98] & $2-3.6$ \\
\hline \multicolumn{2}{|c|}{ Smoking } & [99-103] & $2-3$ \\
\hline \multicolumn{2}{|c|}{ Excessive alcohol use } & {$[104,105]$} & 3 \\
\hline \multicolumn{2}{|c|}{ Underweight } & {$[106,107]$} & $2.0-2.6$ \\
\hline \multicolumn{2}{|c|}{ Age $<5$ yrs (table 3 ) } & [29] & $2-5$ \\
\hline \multicolumn{4}{|c|}{$\begin{array}{l}\text { Level of evidence generally B or C. TNF: tumour necrosis factor. }{ }^{\#}: \text { the adjusted } \\
\text { RR of corticosteroids for the development of tuberculosis has not been } \\
\text { convincingly established. Table adapted and updated from various sources } \\
{[17,22,70] \text {. }}\end{array}$} \\
\hline
\end{tabular}

activity of $M$. tuberculosis, and profiling the genome or components thereof by nucleic acid amplification. This may be supplemented by visualising the interaction between host and pathogen (histopathology) or measuring an immunological response (e.g. delayed-type hypersensitivity skin reaction or cytokines). Specimens from various sites, respiratory and other secretions, blood, and various body fluids or tissues, might have to be obtained to arrive at a definitive diagnosis (A) [108, 109].

In contrast to tuberculosis, latent infection with $M$. tuberculosis has traditionally been diagnosed by a delayed-type hypersensitivity response in the tuberculin skin test using the antigen mixture contained in the so-called purified protein derivative (PPD). IGRAs are novel ex vivo blood tests that have a superior specificity to the tuberculin skin test, while, importantly, comparative test sensitivity varies across study settings for the diagnosis of a recent $M$. tuberculosis infection (C) $[110,111]$. Nevertheless, in tuberculosis contact investigations, positive IGRA results generally correlate better with exposure to an index case than positive tuberculin skin test results [112-116].

Neither IGRAs nor the tuberculin skin test are designed to diagnose tuberculosis as they do not distinguish between latent infection and tuberculosis (A) [110]. Nevertheless, given the high predictive value of a negative test result in a healthy population with a low expected prevalence, the use of a negative IGRA may be justifiable to support exclusion of tuberculosis $[117,118]$. A negative response in an IGRA should nevertheless not dissuade a clinician to diagnose and treat presumptive tuberculosis, especially in immunosuppressed individuals and children [119, 120].

Most desirable is a test for the diagnosis of latent infection with $M$. tuberculosis with the highest prediction of subsequent disease. Some studies do suggest that an IGRA performs tangibly superior in that respect than the tuberculin skin test [34] while others have found this not to be the case [121, 122].

\section{The tuberculin skin test}

The tuberculin skin test is widely used as a screening method for the identification of persons with a positive immune response against $M$. tuberculosis [12]. As a consequence of the development of an immunological memory against mycobacterial antigens, the intradermal administration of tuberculin results in a delayed-type hypersensitivity reaction represented by a local skin induration reaching a maximum $\sim 48-72 \mathrm{~h}$ following antigen injection. A positive reaction is detectable after a median of $\sim 6-8$ weeks after acquisition of infection (C) $[25,123,124]$. The largest transverse diameter of the induration, perpendicular to the long axis of the forearm, is measured in millimetres [125]. The induration margin is either palpated or delineated with a ball-pen [126], neither of which provides assurance against the major source of error, terminal digit preference [127]. Terminal digit preference might be addressed by using inverted callipers instead of the commonly used transparent flexible rulers (C) [128].

The commercially most widely utilised tuberculin in Europe is PPD RT23 (Statens Serum Institut, Copenhagen), standardised against PPD-S [129]. The recommended dose of 2 TU has been demonstrated to be bioequivalent with the international standard dose of tuberculin (5 TU PPD-S) [130].

TABLE 3 Risk of tuberculosis after infection in immune competent children (B)

Age at primary infection
Risk of pulmonary disease or mediastinal lymphatic disease \%
Risk of meningeal or disseminated tuberculosis \%

$\begin{array}{lcc}<\mathbf{1 2} \text { months } & 30-40 & 10-20 \\ \mathbf{1 2 - 2 4} \text { months } & 10-20 & 2-5 \\ \mathbf{2}-\mathbf{4} \text { yrs } & 5 & 0.5 \\ \mathbf{5}-\mathbf{1 0} \text { yrs } & 2 & <0.5 \\ >\mathbf{1 0} \text { yrs } & 10-20 & <0.5\end{array}$




\begin{tabular}{|c|c|c|c|}
\hline \multirow[t]{2}{*}{ TABLE 4} & \multicolumn{3}{|c|}{$\begin{array}{l}\text { Proportion of patients with complete anergy (defined as } 0 \mathrm{~mm} \text { induration size) to the tuberculin skin test and sensitivity } \\
\text { of the tuberculin skin test among patients with non-zero reaction sizes }\end{array}$} \\
\hline & & Anergic \% & [Ref.] \\
\hline \multicolumn{2}{|r|}{ Children with bacteriologically confirmed tuberculosis (including children with life-threatening disease manifestations) } & 14 & [133] \\
\hline \multicolumn{2}{|r|}{ Adults with culture-confirmed tuberculosis and no apparent immunosuppressive disorder } & $2-5$ & {$[131,134,135]$} \\
\hline \multicolumn{2}{|c|}{ Adults with sputum smear-positive tuberculosis and HIV infection } & 25 & [135] \\
\hline
\end{tabular}

\section{Test sensitivity}

The sensitivity of the tuberculin skin test, given a standard dose of tuberculin that is bioequivalent to 5 TU PPD-S (e.g. 2 TU PPD RT23) is fairly well characterised with a distribution belonging to the normal family and a mean of $\sim 16-18 \mathrm{~mm}[131,132]$. From the distribution available from testing nonanergic tuberculosis patients, the sensitivity can be estimated for various cut-off points. In the absence of any relevant cross-reaction resulting from infection with environmental mycobacteria or prior Mycobacterium bovis BCG vaccination, it has be shown that the distribution among nonzero-reacting patients with bacteriologically confirmed tuberculosis is virtually identical to that among healthy children, presumably infected with $M$. tuberculosis, with non-zero reactions [132] and consistent across populations (tables 4 and 5).

However, the proportion of nonreacting patients, and likely healthy individuals infected with $M$. tuberculosis, is determined by various factors associated with relative cellular immunodeficiency or factors related to technical deficiencies in any step of the testing and reading procedure (table 6).

All these factors adversely impact on the otherwise wellcharacterised sensitivity of the tuberculin skin test. HIV infection is the strongest known factor in lowering reactivity to the tuberculin skin test in persons latently infected with $M$. tuberculosis or with tuberculosis [135].

\section{Test specificity}

In contrast to test sensitivity, specificity of the tuberculin varies greatly, due to cross-reactions resulting from prior infection with other mycobacteria. The antigens in tuberculin are specific for the genus Mycobacterium but not for the species M. tuberculosis. Most shared antigens are among the species of the $M$. tuberculosis complex, thus vaccination with BCG results in a virtually identical distribution among reactors shortly after vaccination but reactivity progressively wanes in subsequent years [148]. Different strains of BCG provide different levels of post-vaccinal allergy [149]. Both time elapsed since vaccination [150, 151] and age at vaccination $[148,152]$ influence the extent of

\begin{tabular}{lcc} 
TABLE $\mathbf{5}$ & $\begin{array}{l}\text { Sensitivity of the tuberculin skin test among } \\
\text { patients with nonzero reaction sizes }\end{array}$ \\
Cut-off value & Sensitivity \% & Reference \\
\hline$\geqslant \mathbf{5 m}$ & $95-99$ & {$[131,136]$} \\
$\geqslant \mathbf{1 0} \mathbf{~ m m}$ & $91-95$ & \\
$\geqslant \mathbf{1 5} \mathbf{~ m m}$ & $67-80$ & \\
\hline
\end{tabular}

cross-reactivity that might be seen in tuberculin skin testing, and reactions may be boosted by repeat testing (C) [153, 154]. Thus, the longer the time elapsed since vaccination and the larger the tuberculin reaction size, the higher the probability that the person is infected with $M$. tuberculosis, yet a discernible influence of BCG on reactivity may be retained for many years [155].

Environmental mycobacteria share antigens to a various, but not well-characterised, extent with $M$. tuberculosis, and thus cross-react to different degrees with tuberculin [156-158]. This might be $M$. bovis BCG or environmental mycobacteria. The latter has been most convincingly demonstrated among the subset of lifetime, single-county residents in the largest ever conducted study among US Navy recruits [131]. In some areas (particularly in generally colder and low-humidity areas) there was very little, while in other areas (particularly in hot and humid areas) there was a large amount of sensitisation to environmental mycobacteria affecting tuberculin skin test specificity.

The prevalence of environmental mycobacteria is also known to vary greatly with soil characteristics $[159,160]$. While in the USA, BCG has never been used on a large scale, in those areas in which it was used in a clinical trial, its lasting superimposed effect on test specificity can be seen, even many years after the trial.

\begin{tabular}{l} 
TABLE $6 \quad \begin{array}{l}\text { Possible reasons for a false-negative tuberculin } \\
\text { skin test (generally D) }\end{array}$ \\
Age $<6$ months \\
Age $>65$ yrs [137] \\
Cellular immune defects \\
(e.g. HIV infection, AIDS and lymphoproliferative disorders) \\
Acute or recent severe viral infection (e.g. rubella [138], \\
measles [139, 140] and mononucleosis [140]) and scarlet fever [140] \\
Immunisation with live vaccines within the past 6 weeks (e.g. measles, \\
poliomyelitis, yellow fever, mumps [141] and rubella [142]) \\
Severe debilitating diseases (e.g. malignancies [143]) \\
Systemic high-dose corticosteroid therapy (>15 mg prednisolone \\
equivalent) or treatment with immunosuppressants \\
Advanced pulmonary tuberculosis [133, 144], \\
central nervous system tuberculosis and disseminated tuberculosis [145] \\
Sarcoidosis [146] \\
Malnutrition [147] \\
Window period for manifest immune response to infection \\
with Mycobacterium tuberculosis \\
Application errors (incomplete or subcutaneous tuberculin injection, \\
incorrect quantity of tuberculin, inadequate storage of tuberculin) \\
Reading errors (too early or too late) \\
\hline
\end{tabular}


Given the same prevalence of latent infection with $M$. tuberculosis, balancing errors in sensitivity against those in specificity would require quite different cut-off points. Taking the example of the USA, a cut-off point of $\geqslant 5 \mathrm{~mm}$ to denote a positive test result would be highly predictive for true latent infection in most of the state of Montana but very poorly in most of Florida, taking two conspicuous examples, even if the true prevalence were exactly the same.

Above all, the predictive value will be driven by the underlying true prevalence, which is expectedly high among persons with a history of contact with a tuberculosis patient, while it will be low where no contact can be recalled. Using the data from the aforementioned US Navy recruit study, RUST and THOMAs [161] estimated the predictive value of a reaction size of 10 or more millimeters to be about $80 \%$ if there was, but only about $10 \%$ if there was not history of prior contact.

This makes it exceedingly difficult to define a uniformly applicable cut-off point to denote a positive tuberculin skin test result that optimises the balance between sensitivity and locally variable specificity. Epidemiological data on the prevalence of tuberculin skin test and IGRA test results in different populations and countries in Europe are clearly needed to better address this issue.

\section{IGRA}

Two blood test assays have been developed and marketed for the immunodiagnosis of infection with $M$. tuberculosis. The QuantiFERON ${ }_{\circledR}-\mathrm{TB}_{\text {Gold }}$ and the QuantiFERON ${ }_{\ltimes}$-TB Gold InTube (Cellestis Ltd., Carnegie, Australia) as ELISA and the T-SPOT.TB $B_{\circledast}$ (Oxford Immunotec, Abingdon, UK) as an enzymelinked immunospot assay (ELISPOT). Both types of assay aim to demonstrate the presence of antimycobacterial immune responses against region of difference (RD)-1-encoded early secretory antigenic target (ESAT)-6 and culture filtrate protein (CFP)-10. The RD-1 is present in the genome of all members of the M. tuberculosis complex apart from the BCG substrains of $M$. bovis. The RD-1 sequences are not found in most environmental mycobacteria (also termed "nontuberculous mycobacteria") [162-167] except Mycobacterium kansasii [168], Mycobacterium marinum, and Mycobacterium szulgai [167, 169].

The QuantiFERON-TB ${ }_{\mathbb{B}}$ Gold In-Tube test includes an additional antigen, TB7.7 [170]. which is encoded by a phageinserted region ( $\phi \mathrm{Rv} 2)$ [171]. Both assays use the production of interferon- $\gamma$ within the first day of incubation following antigen contact, compared with a negative control and a positive control as a readout. The cut-offs for the QuantiFERON-TB ${ }_{\circledR}$ Gold In-Tube test and the T-SPOT.TB test to denote test positivity, test negativity or an indeterminate test result provided by the manufacturers are recommended.

An operational advantage of IGRAs over the tuberculin skin test is the additional performance of a negative control that allows assessment of nonspecific background reactivity, and a positive control (the lectin phytohaemagglutinin) of a mitogen stimulus, to assess general T-lymphocyte responsiveness. An absent mitogen response is formally scored as an "indeterminate result", but it provides meaningful information in immunocompromised patients [172]. Therefore, unlike the tuberculin skin test, ex vivo IGRAs may be able to discriminate true negative responses from anergy. Other causes for indeterminate results are technical laboratory errors (e.g. storage in a refrigerator or freezing before incubation resulting in cell anergy) and incorrect handling or transport.

The ELISA allows direct measurement of the concentration of interferon- $\gamma$ in whole blood in stimulated and unstimulated assays. The ELISPOT allows the direct enumeration of the frequency of interferon- $\gamma$-secreting cells among a defined number of incubated peripheral blood mononuclear cells [170]

The sensitivity and specificity of IGRA are listed in tables 7 and $8[109,111]$.

In immunocompromised persons, e.g. individuals with HIV infection [173-175], immunosuppressive therapy [176, 177], or chronic renal failure [178], IGRAs are a more specific and more sensitive marker for a T-cell memory towards $M$. tuberculosis than the tuberculin skin test, but they appear to be less sensitive than in immunocompetent patients (B). The specificity of IGRAs is much superior to the specificity of the tuberculin skin test in individuals with prior BCG vaccination (B). IGRAs require a quality-assured laboratory, and the specifications for blood sampling and transport necessitate established logistic competence. As with the tuberculin skin test, antigen-specific responses in the IGRA are expected to be observed 2-8 weeks following $M$. tuberculosis infection (D) but sufficient data to support this assumption are still lacking. Studies have shown a boosting effect of the tuberculin skin test when given with an interval of $>3$ days on a subsequent IGRA (C) [179-181].

TABLE 7 Summary sensitivity of interferon- $\gamma$ release assays and the tuberculin skin test (TST)

\begin{tabular}{lccccc} 
Series & Diagnostics & Subject & Studies $\mathbf{n}$ & Summary sensitivity (95\% Cl) & Sensitivity range \\
\hline $\mathbf{1}$ & QFT-G & TB patients, adult & 21 & $0.80(0.78-0.82)$ & $0.62-0.95$ \\
$\mathbf{2}$ & QFT-G-IT & TB patients, adult & 6 & $0.74(0.69-0.78)$ & $0.64-0.93$ \\
$\mathbf{3}$ & QFT-G/G-IT & TB patients, child & 9 & $0.82(0.75-0.87)$ & $0.53-1.00$ \\
$\mathbf{4}$ & QFT-G/G-IT, T.SPOT & HIV-infected TB patients & 5 & $0.70(0.60-0.79)$ & $0.63-0.85$ \\
$\mathbf{7}$ & T.SPOT & TB patients & 13 & $0.90(0.86-0.93)$ & $0.83-1.00$ \\
$\mathbf{8}$ & TST & Healthy subjects & 20 & $0.77(0.71-0.82)$ & $0.57-1.00$ \\
\hline
\end{tabular}

QFT-G: QuantiFERON®-TB Gold; QFT-G-IT: QuantiFERON®-TB Gold In-Tube; T.SPOT: T.SPOT-TB®; TB: tuberculosis. Data are taken from the meta-analysis in [109]. 
TABLE 8 Summary specificity of interferon- $\gamma$ release assays and the tuberculin skin test (TST)

\begin{tabular}{lccccc} 
Series & Diagnostics & Subject & Studies $\mathbf{~}$ & Summary specificity (96\% Cl) & Specificity range \\
\hline $\mathbf{1}$ & QFT-G/G-IT & Healthy young adults & 12 & $0.98(0.97-0.99)$ & $0.92-1.00$ \\
$\mathbf{2}$ & QFT-G/G-IT & Healthy young adults, BCG & 8 & $0.99(0.98-1.00)$ & $0.95-1.00$ \\
$\mathbf{3}$ & QFT-G/G-IT & Healthy young adults, BCG & $0.96(0.94-0.98)$ & $0.89-0.99$ \\
$\mathbf{4}$ & T.SPOT & Predominantly BCG vaccinated & 8 & $0.93(0.86-1.00)$ & $0.85-1.00$ \\
$\mathbf{5}$ & TST & BCG not vaccinated & 6 & $0.97(0.95-0.99)$ & $0.93-1.00$ \\
$\mathbf{6}$ & TST & BCG vaccinated & 6 & $0.59(0.46-0.73)$ & $0.35-0.79$ \\
\hline
\end{tabular}

Several studies under series 1 are included in series 2 or 3. QFT-G: QuantiFERON®-TB Gold; QFT-G-IT: QuantiFERON $\mathbb{E}-$ TB Gold In-Tube; T.SPOT: T.SPOT-TB®; TB: tuberculosis. Data are taken from the meta-analysis in [109]

\section{Other diagnostic tools}

\section{Chest radiography}

Chest radiography is a sensitive tool in identifying pulmonary tuberculosis. The reported proportion of normal chest radiographs among culture-proven pulmonary tuberculosis cases is commonly reported to be $\leqslant 10 \%$ in the absence of recognised immunosuppression [182-184]. HIV infection may substantially alter radiographic findings $[185,186]$ and the proportion of patients with normal chest radiographs becomes larger with increasing immunosuppression (D) [183, 187]. A thoracic computed tomography image may be indicated in individual cases to improve the radiological diagnosis of tuberculosis. Even though some features on chest radiograph or thoracic computer tomography may be suggestive of tuberculosis, there are no images that are pathognomic for tuberculosis. In persons with latent infection with $M$. tuberculosis, the chest radiographs are usually normal, though abnormalities suggestive of prior tuberculosis such as calcification or fibrotic lesions may be present.

\section{History}

Each tuberculosis contact needs to be interviewed briefly to obtain more information on the factors summarised in table 9 (symptoms, the likelihood of a recently acquired infection, remote infection, prior tuberculosis, the susceptibility of the contact and the probability of treatment completion) in order to assess the individual's risk in relation to the previously established infectiousness of the source case and facilitate the interpretation of the results of the investigation.

\section{Physical examination}

Physical examination is indicated when the contact person presents with symptoms suggestive of tuberculosis, particularly if a chest radiograph is normal and a diagnosis of extrapulmonary tuberculosis with readily ascertainable signs (lymphatic, osteoarticular, cutaneous and other manifestations) must be considered.

\section{Sputum}

European standards for laboratory examinations have been published [188]. Any contact who has an abnormal chest radiograph or has symptoms suggestive of tuberculosis should have sputum specimens collected and examined. If no sputum is spontaneously produced, it is recommended to obtain an induced sputum specimen which has a similar yield as specimens obtained with bronchoalveolar lavage [189]. While gastric lavage is specific [190], it has poor sensitivity and is used as a last resort only in children from whom no direct respiratory specimen can be obtained (D).

\section{Nucleic acid amplification tests}

Nucleic acid amplification tests are expensive and complex. They have excellent specificity and may provide results within 3-24 h, but they have variable and often poor sensitivity in patients in whom sputum smears are negative for acid-fast bacilli [191, 192]. The main indication for nucleic acid amplification tests is thus to obtain a rapid identification of the species among bacteriologically positive specimens and determination of the strain's drug susceptibility pattern [192].

\section{TABLE 9 Information to be obtained during the interview of the tuberculosis contact}

Degree of exposure to the index case and location of possible transmission

Risk of prior infection with Mycobacterium tuberculosis (e.g. foreign-born or prior tuberculosis contact)

$B C G$ vaccination status

Previous TST and/or IGRA result

Age

Tuberculosis history (tuberculosis, latent infection with M. tuberculosis, previous antituberculosis chemotherapy or preventive therapy)

Medical history and comorbidity (immune status (table 2), risk of hepatitis or co-medication)

Symptoms of tuberculosis

Conditions associated with reduced adherence

BCG: Bacille Calmette-Guérin; TST: tuberculin skin test; IGRA: interferon- $\gamma$ release assay. 


\begin{tabular}{|c|c|}
\hline \multirow[t]{3}{*}{ Intensity of exposure } & $\begin{array}{l}\text { Degree of proximity (talking distance) between } \\
\text { the contact and the index, if exposure was only } \\
\text { outdoors }\end{array}$ \\
\hline & $\begin{array}{l}\text { Concentration of tubercle bacilli in the ambient } \\
\text { indoor air, determined by cough intensity and } \\
\text { bacillary load in the sputum }\end{array}$ \\
\hline & $\begin{array}{l}\text { The volume of air shared and quality of air } \\
\text { circulation and ventilation indoors }\end{array}$ \\
\hline Duration of exposure & $\begin{array}{l}\text { Cumulative time of contact during the putative } \\
\text { period of infectiousness period }\end{array}$ \\
\hline
\end{tabular}

The information in this table is taken from $[55,194,195]$.

\section{RISK ASSESSMENT AND PRIORITISATION OF TUBERCULOSIS CONTACTS}

Various national guidelines agree on the basic approach to the organisation of contact investigation as an ordered sequence of priority decisions $[15,16,18,19]$. The organisation of contact investigation is based on a risk assessment, for which the need to screen contacts is prioritised on the basis of the putative infectiousness of the index case, duration of exposure to the index case, and risk of tuberculosis among a contact in case infection had been acquired. There are two possible strategies: 1) identification and evaluation of high priority contacts with a prolonged exposure, and expansion of investigation according to the individual risk of progression to disease (risk group approach) [18]; and 2) identification and evaluation of highpriority contacts and expansion to medium-priority contacts according to evidence of transmission among high priority contacts and identification of those with a particularly high risk of progression to tuberculosis if infected (modified "stonein-the-pond" principle) [193].

Contacts may be defined as "high priority" even in the absence of prolonged exposure, such as exposure to ambient air in a closed or poorly ventilated room, which is likely to still contain a high concentration of infectious droplet nuclei, even after the putative source case has left the room. A similar situation arises with brief exposure to a particularly high concentration of bacilli, such as might be the case during aerosol-producing manoeuvres like sputum induction, bronchoscopy, dental or otorhinolaryngolocial examination, or resuscitation measures [18].

The index patients should be interviewed about their social network and activities during the putative period of infectiousness in order to identify contacts who might have been subject to relevant exposure. Subsequently, contacts are grouped according to the degree of exposure and those at increased risk of progression to tuberculosis. This approach provides a framework for an ordered priority classification of individuals and groups from whom contact investigations are commenced and conducted.

The degree of exposure depends on the intensity and duration of exposure as shown in table 10. Contacts can be classified into groups around the source case according to the degree of exposure (tables 11 and 12). Contacts with conditions predisposing to a higher risk of progression to tuberculosis following infection (listed in table 2) will need to be identified and given priority for evaluation. When the different groups of contacts have been identified and located, the contacts can be classified into priority groups according to the degree of exposure and susceptibility (table 12).

\section{TABLE 11 Classification of contacts around the index case according to the degree of exposure}

\section{1st circle of contacts (inner circle)}

Close household contacts

Close nonhousehold contacts

2nd circle of contacts (middle circle)

Casual contacts

3rd circle of contacts (outer circle)

Community contacts

\section{Description}

Those who live in the same household as the infectious case. Household contacts are considered, by definition, to share breathing space on a daily basis with the source case.

Close nonhousehold contacts may include those persons with short exposure times to direct face-to-face streams of air with a particularly high density of infectious droplet nuclei, such as may occur during bronchoscopy or otorhinolaryngeal examination of patients with hence untreated sputum smear-positive tuberculosis, and similar situations. For all other close nonhousehold contacts, an arbitrarily defined cumulative exposure time of $8 \mathrm{~h}$, if the index is sputum smear-positive, or $40 \mathrm{~h}$, if only sputum culture-positive has been recommended as a guiding principle [18]. This group also includes contacts with regular, prolonged contact with the source case, who share breathing space but do not live in the same household or who have spent time with the source case in a confined space, such as a car, sweatshop or prison cell. These may also include contacts, such as close friends and colleagues.

Those who spent less time with the infectious case. These may include frequent visitors to the home, friends, relatives, school or class mates, colleagues at work or leisure contacts, members of a club or team, or passengers in adjoining seats during aircraft travel of $>8 \mathrm{~h}$ [201].

Those living in the same community or attending the same school, sports club or workplace who may have had sporadic contact. 


\begin{tabular}{ll}
$\begin{array}{l}\text { TABLE } 12 \text { Priority groups of contacts } \\
\text { High-priority contacts } \\
\text { First-circle contacts at increased risk of } \\
\text { developing tuberculosis following infection } \\
\text { Other first-circle contacts } \\
\text { Second-circle contacts at increased risk of } \\
\text { developing tuberculosis following infection } \\
\text { Second-circle contacts } \\
\text { Third-circle contacts at increased risk of } \\
\text { developing tuberculosis following infection } \\
\text { Third-circle contacts or outer circle }\end{array}$ \\
\hline
\end{tabular}

\section{EVALUATION OF TUBERCULOSIS CONTACTS AND TIMING}

To proceed in an orderly manner in a tuberculosis contact investigation, high-priority contacts are evaluated first for latent infection with $M$. tuberculosis and tuberculosis. Only once results from these examinations are known is a decision taken on how next to proceed. Figure 1 and table 13 give a schematic overview of when and how to evaluate the different priority groups.

In the event of a noninfectious index case likely due to recently acquired infection without a known source, a single evaluation of close contacts through a tuberculin skin test and/or IGRA and chest radiographic examination is advocated to identify the source with active pulmonary tuberculosis and other individuals infected with $M$. tuberculosis by the same source case among the close contacts.

\section{Immediate evaluation of (vulnerable) high-priority contacts}

If the index case has a high potential of infectiousness, e.g. positive on direct sputum smear examination [202], an initial evaluation of first-priority contacts at particularly high risk of tuberculosis (table 2), and close contacts with symptoms suggestive of tuberculosis is indicated as swiftly as possible to reduce the risk of progression to tuberculosis by preventive intervention or, if present already, reduce morbidity and unnecessary delay in the diagnosis of secondary cases. For this purpose, all contacts should ideally be informed about the purpose and proceedings of the contact investigation $<7$ days after the identification of the index case. Immediate evaluation of the potentially most vulnerable contacts, specifically children aged $<5$ yrs, may uncover latent infection with $M$. tuberculosis or tuberculosis in a considerable proportion if the index case had been infectious for a prolonged period of time.

Immediate evaluation of other high priority contacts is recommended, e.g. in the Netherlands [19], as it is expected to provide preliminary empirical evidence on the actual infectiousness of the index patient and allow recent conversion to be distinguished from remote infection with $M$. tuberculosis by sequential tuberculin skin testing or IGRA. The highest priority should be given to a definitive assessment 2 months after adequate chemotherapy was initiated in the index case. Unless they have documented pre-existing latent infection

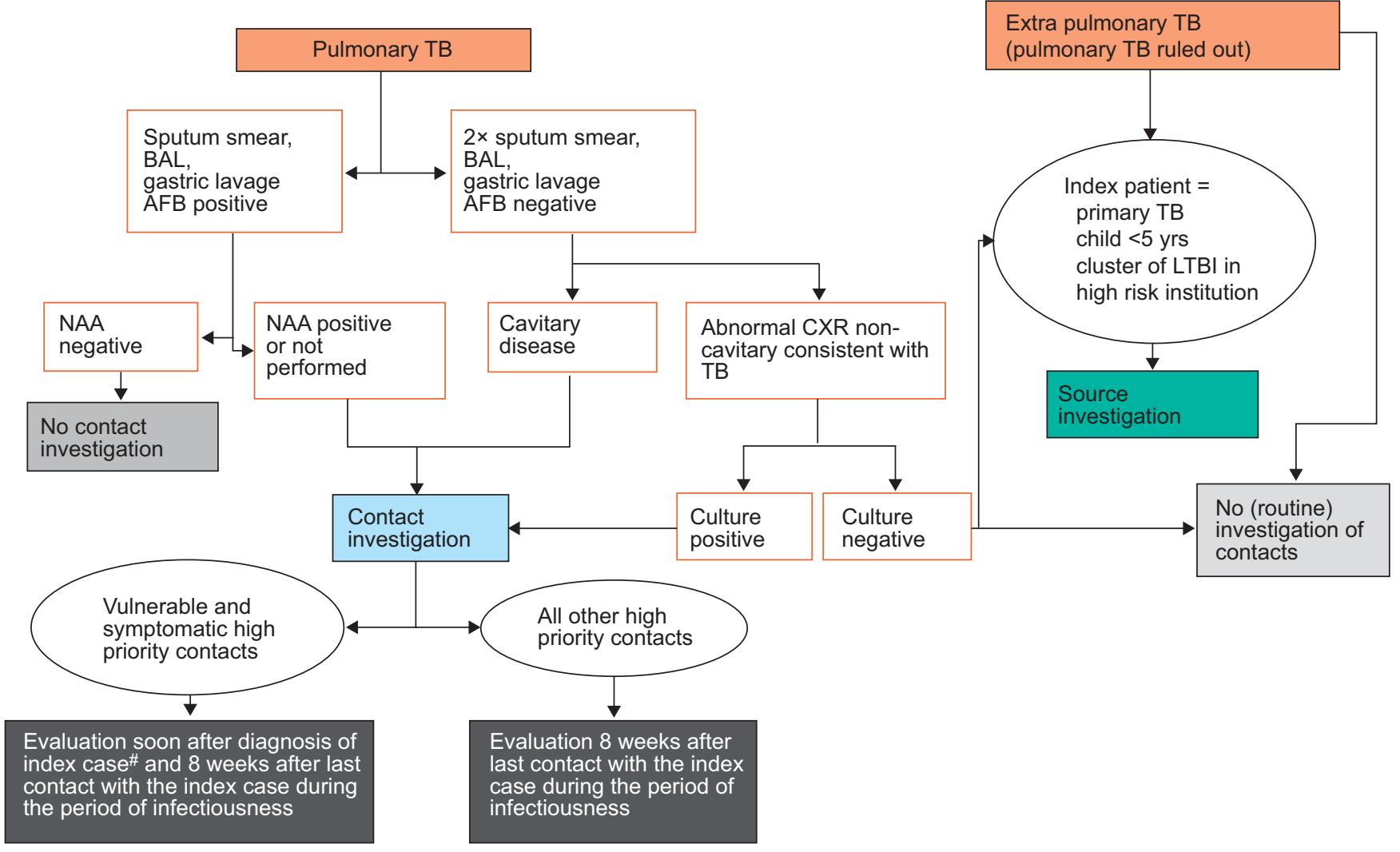

FIGURE 1. Need and timing of contact investigation. TB: tuberculosis; BAL: bronchoalveolar lavage; AFB: acid-fast bacilli; NAA: nucleic acid amplification; CXR: chest radiograph; LTBI: latent TB infection. * : first evaluation, other priority or vulnerable medium-priority contacts optional. 
TABLE 13 Organisation and timing of evaluation of contacts of infectious tuberculosis patients

Contact group

Timing

$<1$ week after diagnosis

(or as soon as possible)

After window period $(8$ weeks after last contact with the index case during the period of infectiousness)

\begin{abstract}
High-priority
Vulnerable close contacts and contacts with symptoms of tuberculosis Other close contacts
\end{abstract}

\section{Medium-priority}

Vulnerable casual contacts

Other medium priority contacts

Low-priority
TST $^{\# / / G R A ~ a n d ~ c h e s t ~ r a d i o g r a p h " ~}$ Optional or when proved transmission among (vulnerable) close contacts: $\mathrm{TST}^{\# / / G R A}$ and chest radiograph

When proved transmission among high priority contacts: TST ${ }^{\# / I G R A}$ and chest radiograph
TST/IGRA and chest radiography TST/IGRA

TST/IGRA

When proved transmission among high priority contacts: TST/IGRA

When proved considerable transmission among medium priority contacts: TST/IGRA

TST: tuberculin skin test; IGRA: interferon- $\gamma$ release assay. ${ }^{\#}$ : when there is a history of a previous positive tuberculin skin test, tuberculosis or latent infection with $M$. tuberculosis, no tuberculin skin test should be administered; ": in bacille Calmette-Guérin-vaccinated patients, it is recommended not to use the tuberculin skin test in the first round of examination to avoid boosting in the second round.

with $M$. tuberculosis or previous or current tuberculosis, highpriority contacts should be evaluated for infection with $M$. tuberculosis. Some national guidelines give preference to primary testing by an IGRA test, in particular in immunocompromised patients [203], while others recommend an IGRA test for household contacts of sputum smear-positive cases who have a negative tuberculin skin test [16]. In the case of a history of prior tuberculosis or latent infection with $M$. tuberculosis, chest radiography is always indicated to exclude current tuberculosis. A radiograph may be supplemented by IGRA if prior infection is only documented by a tuberculin skin test. If the chosen test for latent infection is the tuberculin skin test, attention should be paid to the potential of boosting to repeat testing, which may be particularly important among BCGvaccinated contacts. The tuberculin skin test may thus be postponed (where not in conflict with overriding circumstances as detailed above) until $\geqslant 8$ weeks after the last relevant exposure to the index case. In individuals with a history of BCG vaccination, an IGRA is the preferred test for latent infection with $M$. tuberculosis. Chest radiography is indicated at the same time as the initial tuberculin skin test or IGRA if the contact: 1) has symptoms suggestive of tuberculosis; 2) is HIVinfected or has another immunosuppressive disorder or medications; 3 ) is $<5$ yrs of age; or 4 ) the tuberculin skin test reaction size exceeds $5 \mathrm{~mm}$ or the initial IGRA is positive.

High-priority contacts with a tuberculin skin test reaction of $\geqslant 5 \mathrm{~mm}$ should be evaluated by IGRA [11, 12]. A tuberculin skin test reaction size of such a small diameter has a relative high sensitivity but poor specificity, the latter of which is addressed by sequential testing with IGRA (D) [204]. In populations where the sensitivity and specificity of the tuberculin skin test is thought to be high such as in unvaccinated children, IGRA may not be superior to tuberculin skin testing [205], and thus the value added by a sequentially used IGRA limited.

Any contact who has an abnormal chest radiograph or symptoms compatible with tuberculosis should have a minimum of two sputum specimens collected for examination, regardless of the tuberculin skin test or IGRA result.

Once tuberculosis has been ruled out, primary prophylactic treatment (that is preventive therapy without definitive proof that latent infection has been acquired) should be initiated immediately in vulnerable high-priority contacts, namely children $<5$ yrs of age and contacts with HIV infection or other severe immunodeficiency, even if the result the of tuberculin skin test is $<5 \mathrm{~mm}$ induration and/or an IGRA is negative.

\section{Defining clinically workable cut-off points for the tuberculin skin test interpretation when IGRA are not available}

Where only the tuberculin skin test is available, a strategy different from the general recommendation that a positive reaction in a tuberculin skin test should be followed by an IGRA is in place. In this scenario, the general approach in screening using a sensitive test first, followed by a more specific test, is applied. In the first scenario, a balance of the errors resulting from deficiencies in both sensitivity and specificity at a given test criterion need to be applied.

Determining which cut-off points to choose to denote test positivity must take numerous factors into account concerning the variable sensitivity and specificity of the tuberculin skin test in different geographic settings, and variable levels of likelihood of infection as described before.

The problem is further compounded if there is a high likelihood of infection and the usually well-characterised test sensitivity is compromised, such as is the case among persons 
with immunosuppressive disorders. An additional concern that enters the decision on making cut-off points is that the consequences of missing an infection (choosing high specificity over high sensitivity) are not the same for all persons concerned. For instance, not only is the risk of progression from latent infection to tuberculosis increased among infants and other very young children compared with children of e.g. primary school age; the risk of dissemination with a fatal or seriously disabling outcome is also much increased among the former, should they develop tuberculosis. In principle, this should also apply to the cut-off points for IGRAs and, indeed, the cutoff points recommended by the manufacturers have been questioned by some authors [179, 206, 207].

Furthermore, for clinical convenience, cut-off points are generally made, not along biological criteria, but to allow easy memorising, such as multiples of five. Such cut-off points have the additional disadvantage of being prone to digit preference [208]. What is proposed here is thus not an exact and unalienable recommendation, and may indeed be subject to improved modifications in various European countries that have better epidemiological background information, specific to the country, on prevalence of cross-reactions with environmental mycobacteria, extent of BCG vaccination, and, notably, background prevalence of infection with $M$. tuberculosis. The summary recommendations given in table 14 are thus meant to be a guidance for future European guidelines, and for countries not having their own, and perhaps superior recommendations, rather than an attempt to override preexisting, epidemiologically defined criteria.

In situations with a low likelihood of infection, increasing the cut-off point to $15 \mathrm{~mm}$ will result in a substantial gain in specificity. However, for persons with a high risk of developing tuberculosis, such as close contacts of infectious tuberculosis patients, the cut-off point of $15 \mathrm{~mm}$ will result a loss of sensitivity (see table 5). Therefore, in the context of investigation of close contacts, a tuberculin skin test induration cut-off of $\geqslant 10 \mathrm{~mm}$ in immune-competent, non-BCG vaccinated hosts, $\geqslant 15 \mathrm{~mm}$ in immune-competent, BCG-vaccinated hosts, and $\geqslant 5 \mathrm{~mm}$ in immunocompromised hosts seem to be the most appropriate for the diagnosis of latent infection with $M$. tuberculosis based on tuberculin skin testing alone. In non-close contacts and when screening individuals with a low likelihood of infection, a tuberculin skin test induration cut-off of $\geqslant 15 \mathrm{~mm}$ in immune competent non-BCG vaccinated and $\geqslant 10 \mathrm{~mm}$ in the immunocompromized host is suggested for the diagnosis of latent infection with $M$. tuberculosis based on tuberculin skin testing alone. A negative tuberculin skin test is not reliable to exclude infection in HIV-seropositive individuals (table 14) [135].

\section{Evaluation of high-priority contacts after the "window period"}

The "window period" is the interval between acquisition of infection with $M$. tuberculosis and the point in time when an immunologic response becomes measurable as described previously. In all high-priority contacts, or in case of an initially negative tuberculin skin test or IGRA in a high priority contact, the evaluation should be performed or repeated when $\geqslant 8$ weeks (1-2 weeks beyond the median window period) have passed since the last relevant exposure to the index case while infectious. If the index case was treated at home, the second tuberculin skin test in household contacts should be performed 8 weeks after the putative period of transmissibility has ended.

\section{TABLE 14 Recommended cut-off for tuberculin-skin test (TST) positivity in a contact investigation when interferon- $\gamma$ release assays are not available}

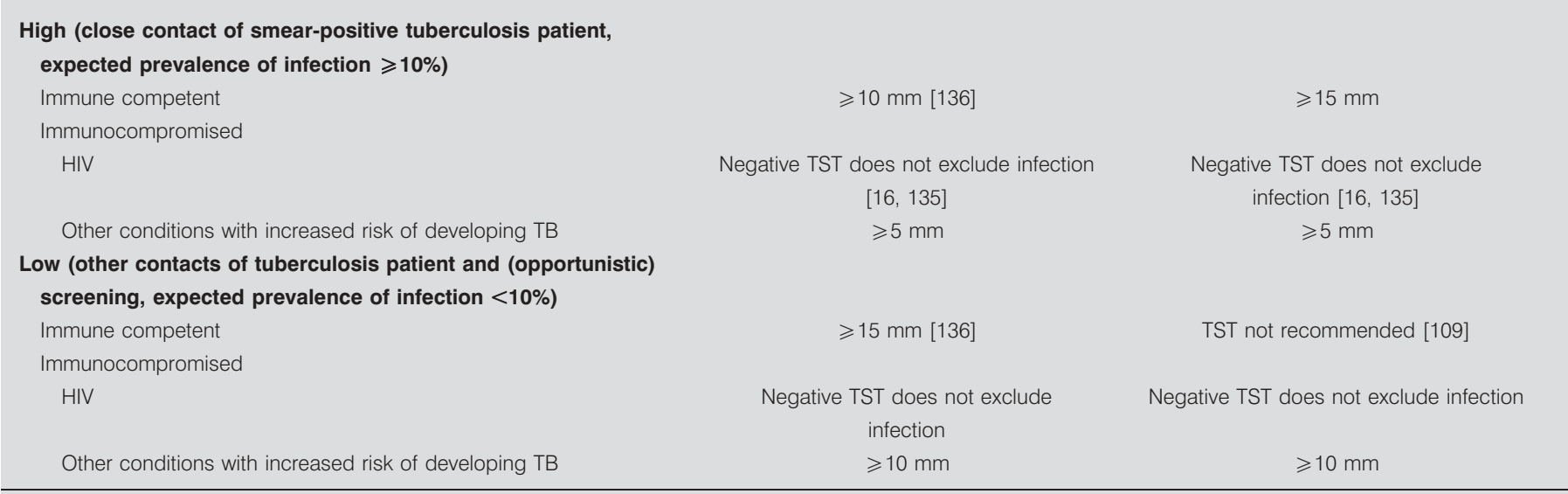


In children $<5$ yrs of age, primary prophylactic treatment may be stopped if the repeat tuberculin skin test remains negative. However, if the child is $<6$ months of age, a full course of prophylactic or preventive therapy should be completed, even when the second tuberculin skin test or IGRA remains negative. As a minimum, it should be continued until the child is old enough ( $>6$ months of age) to mount a presumably more reliable response to a tuberculin skin test or IGRA. Contacts with HIV infection or other severe immunosuppressive disorders should be re-evaluated after completion of 2 months of preventive therapy. If tuberculosis can still be ruled out and the mandatory chest radiograph remains normal, they should complete the full course of preventive therapy.

\section{Assessing the need for expanding contact investigations}

In the risk group approach, other vulnerable contacts according to the individual risk of progression may be included in the evaluation. Other medium-priority contacts are usually not evaluated. In the concentric-circles approach, the contact investigation does not need to be expanded to the mediumpriority groups, unless there is the following evidence of recent transmission among the high priority contacts. 1) Contacts with tuberculin skin test or IGRA conversions. 2) Young children with a positive tuberculin skin test reaction or IGRA. 3) Contact with tuberculosis detected. 4) The observed prevalence of infection is, importantly, higher than the expected age-specific background prevalence, (e.g. estimated to be $\sim 10 \%$ in the USA [15], or at least twice the prevalence of a similar population without recent exposure, whichever is greater). However, this criterion may be difficult to implement in settings where information on background prevalence of infection with $M$. tuberculosis is unknown or cannot be reasonably estimated.

\section{Evaluation of medium-priority contacts}

In the concentric-circles approach, the need to investigate medium-priority contacts arises when there is evidence of transmission among high-priority contacts. Medium-priority contacts of sputum smear-negative tuberculosis patients should not be screened without evidence that transmission is likely to have occurred. Medium-priority contacts are usually evaluated only once after the window period and the investigation of highpriority contacts documents evidence of transmission. There are, however, circumstances where the pressure to act is high, such as when there has been exposure of vulnerable groups among medium-priority contacts, when there has been a long diagnostic delay in a patient considered to be highly infectious, or if secondary cases are found among medium-priority contacts. Under such circumstances, the evaluation of mediumpriority contacts may be planned immediately after the first evaluation of the high-priority contacts.

Low-priority contacts are not evaluated unless there has been proven, considerable transmission among medium-priority contacts. When evaluated, they are only examined once after the window period.

For practical purposes, it is recommended to plan the evaluation of susceptible casual contacts only after evidence of transmission among close contacts has been found, except in situations where susceptible persons among casual contacts have been identified already, where a large group of susceptible casual contacts have been exposed, where the risk of infection and progression to disease of susceptible casual contacts is deemed high, or if the group of high-priority contacts identified is too small to reflect the infectiousness of the index patient.

\section{MANAGEMENT OF LATENT INFECTION WITH $M$. TUBERCULOSIS \\ Treatment of latent infection with $\mathrm{M}$. tuberculosis}

For the diagnosis of latent infection with $M$. tuberculosis, a positive tuberculin skin test and/or IGRA, a normal chest radiograph (or calcified lesions only, or as bacteriologically assured negative fibrotic lesions), and absence of signs or symptoms compatible with tuberculosis are required. Pursuing the identification of latent infection with $M$. tuberculosis is only justified if it results in an intervention where indicated, such as preventive therapy or, if contra-indicated, follow-up of those at risk of developing tuberculosis. It is also important to ensure that those not at risk do not receive unnecessary treatment $[209,210]$. Where available, resources permit, the expected prevalence of infection is low, and/or prior BCG vaccination the rule, it is preferable to seek confirmation of a positive tuberculin skin test by an IGRA test, if the latter is not already the primary choice [203]. In general, a negative IGRA result overrules a positive tuberculin skin test result in adults. However, diverting IGRA and tuberculin skin test results should be carefully considered as an indication for preventive chemotherapy in vulnerable high-priority contacts.

An appropriate tuberculosis control and elimination strategy necessitates carefully weighing the benefits of preventing tuberculosis in the infected individual and in the community against the risk of drug-induced liver injury during the period of treatment. It also takes the risk of re-infection into account. Adverse drug events and nonadherence threaten the completion of treatment and treatment may be inefficacious if it does not match the drug susceptibility pattern of the source case's strain.

Table 15 summarises the evidence level for commonly used and recommended regimens for the treatment of latent infection with $M$. tuberculosis. The strongest evidence for a preventive therapy regimen is a choice between 12 months of isoniazid and 3 months of rifampicin plus isoniazid (A). Different recommendations on the optimum duration of isoniazid preventive therapy are based on a difference of opinion as to whether the regimen choice should be based on efficacy or effectiveness [21].

When the source case is unknown or when there are no drug susceptibility test results available, the probability that the contact has been infected by a resistant strain should be assessed and the choice of the preventive treatment regimen be made accordingly.

Adverse drug events may affect patient adherence. Patients must be fully informed both about minor inconveniences (such as orange discoloration of tears and urine from rifampicin) and potentially serious adverse events, such as drug-induced hepatic injury, and must be carefully evaluated for concomitant use of other medications to determine the potential of drug-drug interactions [219]. In particular, females using oral contraceptives must be advised about the potential of their failure when given rifampicin, and the alternative use of a 
TABLE 15 Treatment regimens for latent infection with M. tuberculosis [21]

\begin{tabular}{lcccc} 
Treatment regimen & [Ref.] & & Efficacy/effectiveness & Level of evidence \\
\hline $\mathbf{1 2}$ months isoniazid & {$[26,211]$} & $12 \mathrm{H}$ & $93 \% / 75 \%$ & $\mathrm{~A}$ \\
$\mathbf{9}$ months isoniazid & {$[195,212,213]$} & $9 \mathrm{H}$ & $\sim 90 \%$ & $\mathrm{C}$ \\
$\mathbf{6}$ months isoniazid & {$[195]$} & $6 \mathrm{H}$ & $69 \% / 65 \%$ & $\mathrm{~A}$ \\
$\mathbf{4}$ months rifampicin & {$[214-216]$} & $4 \mathrm{R}$ & $\mathrm{C}$ \\
$\mathbf{3}$ months isoniazid-rifampicin & {$[217,218]$} & $3 \mathrm{HR}$ & Equivalent to $6 \mathrm{H}$ & $\mathrm{A}$ \\
\hline
\end{tabular}

regimen based on isoniazid alone must be explored. In many European cultures, alcohol consumption is common, predisposing to liver injury prior to preventive therapy, the most important risk factor for toxic isoniazid hepatitis in preventive therapy [211]. Patients judged to have an increased risk of drug-induced liver injury should be offered regular evaluation of liver enzymes. There are indications that a shorter treatment regimen and offering the patient a choice between treatment regimens results in a lower proportion of patients interrupting the treatment [220]. To ensure treatment adherence, regular support visits and follow-up are advisable.

\section{Alternatives to treatment}

When preventive therapy is prematurely discontinued or not even initiated, the contact should: 1) be educated thoroughly about symptoms and signs of tuberculosis, and the need for immediate medical evaluation if symptoms occur; 2) be educated thoroughly about the need for medical evaluation if they receive immunosuppressive therapy (such as tumour necrosis factor- $\alpha$ inhibitors, high-dose corticosteroid treatment, immunosuppressive therapy for malignancies, etc.) or if they have or develop other immunocompromising conditions.

Follow-up by annual or biannual radiographic evaluation among persons not receiving preventive therapy is used by some to ascertain the emergence of radiographically manifest tuberculosis. Such practice is of doubtful effectiveness if the experiences from the studies on periodic mass-screening are of any relevance, showing that the majority of new tuberculosis cases occur between screening rounds [221].

\section{Management of contacts of cases with multidrug- and extensively drug-resistant tuberculosis}

Drug resistance is an important issue in the management of tuberculosis, as it may prolong the period during which patients are infectious and treatment efficacy may be compromised. There is no convincing evidence that drug resistance per se modifies the probability of transmission [222]. However, the consequences of acquiring an infection with a multidrugresistant strain of $M$. tuberculosis are much more serious, and not all resistance-conferring mutations lower the fitness of $M$. tuberculosis [223, 224], and any lowered fitness is irrelevant in immunocompromised patients [225]. Furthermore, multidrugresistant tuberculosis needs prolonged treatment with drugs that are generally less bactericidal then some of the first-line drugs. All this has repercussions on contact investigations. Despite the scarcity of information on how to deal with contacts putatively infected by such a case, the evaluation of contacts of patients with multidrug-resistant tuberculosis may be accorded higher priority. It may be necessary to re-examine contacts who have had ongoing exposure to the index case before adequate treatment was initiated and isolation measures were taken.

There are no randomised controlled trials assessing the efficacy of treatment of latent infection with multidrug-resistant $M$. tuberculosis or indeed extensively drug-resistant tuberculosis, and the scarce observational studies are hardly informative as to best practice [226]. Those who advocate preventive therapy in such cases recommend that the regimen should include two orally administered drugs, to which the putative infecting strain is susceptible. No specific preventive therapy regimen can currently be recommended because of lack of evidence and the high risk of drug-induced liver injury [227, 228].

Contacts presumably infected with a multidrug-resistant or extensively drug-resistant $M$. tuberculosis strain, whether receiving preventive therapy or not, should: 1) be thoroughly informed about symptoms and signs of tuberculosis and the need for immediate medical evaluation if symptoms occur; 2) be thoroughly informed about the need for medical evaluation if they would receive immunosuppressive therapy; 3) be assessed for risk factors for developing tuberculosis (table 2); and 4) receive regular and careful clinical follow-up for a period of $\geqslant 2$ yrs. If tuberculosis develops, prompt initiation of treatment with a regimen designed to treat multidrug-resistant tuberculosis is recommended [229-231].

\section{OUTBREAK MANAGEMENT}

The definition of an outbreak, agreed upon at the Wolfheze Workshop Conference "the occurrence of two or more tuberculosis cases, outside the household setting, with an epidemiological and/or molecular link occurring within one year" [232].

Various measures, beyond those usually undertaken during routine contact investigation of a single case, may be necessary once the occurrence of an outbreak has been determined. For the investigation of any outbreak, a case definition is required [233]. An outbreak control committee with all relevant stakeholders should be constituted (D). Membership of this committee will vary by country, but preferably includes a tuberculosis or respiratory physician, public health staff, a microbiologist and an administrative lead (D). This committee should decide on further action. Such action may include several overlapping contact investigations; coordination and proper communication to the exposed community, other healthcare providers and the media; analytical epidemiological studies; and additional public health resources. Early and 
regular dissemination of information is critical to minimising levels of anxiety in the community, and is likely to result in improved cooperation and adherence to recommendations (D).

DNA fingerprint technology enables the identification of molecular clusters [234, 235, 236] and exclusion of pseudooutbreaks due to laboratory cross-contamination [237] (C). Mycobacteriology laboratories have utilised DNA fingerprinting data, coupled to dates of specimen processing, to identify cases that are probably due to cross-contamination. Molecular evidence of clustering should always be combined with information on epidemiological and social relationships between clustered cases. This is an essential step in confirming known, and identifying previously unknown, spatial or temporal associations between outbreak cases. Secondary cases with an unexpected link to a known index case may represent a failure of conventional contact investigation in reaching the exposed population or may reveal previously unobserved transmission in the community. Continued occurrence of cases in clusters may suggest ongoing transmission that is not sufficiently controlled by conventional contact investigation and supports the use of other measures, such as screening of a subgroup with a high risk of infection.

In low-incidence settings, outbreak management through cluster surveillance may contribute to the prevention of transmission and provides a tool to evaluate the effectiveness of contact investigation practices [238].

\section{MONITORING AND EVALUATION OF CONTACT INVESTIGATION}

Monitoring and evaluation of the results of a contact investigation will enable investigators to: 1) assess whether all persons with an increased risk of having become infected have been informed and/or screened; 2) assess whether other exposed groups need to be targeted for contact investigation; 3) evaluate the organisation, performance and effectiveness of contact investigation procedures; and 4) provide data for evidencebased guidelines on contact investigation. The evaluation of aggregated results on the yield of contact investigations may be useful to assess the efficacy of this intervention and the appropriate use of resources. Table 16 lists potential indicators and objectives for the evaluation of contact investigations as suggested by participants at the Wolfheze (The Netherlands) meeting in 2006 and recommended by the US Centers for Disease Control and Prevention [15].

For the purpose of evaluation, the results of each contact investigation should be reported to the appropriate authorities involved in the contact investigation. Data should be sent to a central coordinating health authority for further evaluation.

\section{CONTACT INVESTIGATIONS IN CONGREGATE AND OTHER SPECIAL SETTINGS}

The occurrence of a tuberculosis case in congregate settings, such as schools, prisons, hospitals or other institutions where large groups of people are confined to areas with limited air circulation, requires a more tailored approach. Such institutions have a special responsibility towards the health of their communities and may feel the need to expand contact investigation at an early stage to a larger group of contacts, or contacts with a lower priority. The need for further investigation beyond routine contact tracing should, however, be determined by the infectiousness of the source case, the degree of overcrowding, and the susceptibility of the population (e.g. hospital, children). The decision-making process also takes into account any evidence of transmission and the effectiveness of interventions. Individuals travelling on ships, trains and aeroplanes may need contact investigation. Airborne transmission from animals [239], and humans with tuberculosis caused by $M$. bovis may occur rarely, and may require investigation [240]

\section{Prisons}

Global guidelines for the management of tuberculosis in prisons focus on early detection and infection control, adequate treatment of susceptible and multidrug-resistant tuberculosis, and on case-holding after release from prison [241, 242]. In prison populations, the prevalence of tuberculosis is presumed to be higher than in the civilian population. While population groups with a high risk of infection with $M$. tuberculosis and tuberculosis, such as those addicted to alcohol or illicit drugs, the homeless, the mentally ill, foreign-born persons and former prisoners, often contribute a disproportionately high proportion of the incarcerated, there is remarkably little evidence of a considerably increased risk of infection with $M$. tuberculosis among occupations working in the prison system in low-incidence countries [243, 244]. Many lowincidence countries screen detainees for tuberculosis upon incarceration. Inmates and staff who are exposed to a case with bacteriologically confirmed respiratory tract tuberculosis should be investigated using the principles of risk assessment for contact investigation and outbreak management (D) [245]. Investigations should be pursued in close collaboration with the local public health and tuberculosis control authorities.

TABLE 16 Recommended objectives for contact investigations, by key indicators

Key indicator

Proportion of infectious patients with at least one contact listed

Proportion of high-priority contacts who are evaluated for tuberculosis and latent infection with $M$. tuberculosis

Proportion of infected contacts who begin preventive therapy for latent infection with $M$. tuberculosis

Proportion of contact investigations concluded within 3-4 months after the diagnosis of the index patient

Proportion of contacts who complete preventive therapy for latent infection with $M$. tuberculosis
Objective

Adapted from [15] 
Continuation of preventive and curative therapy should be ensured when contacts are released, transferred or paroled.

\section{Air travel}

The revision of International Health Regulations and the attention given to the emergence of multidrug- and extensively drug-resistant tuberculosis [246] also led to a renewed focus on air travel and airborne transmission on flights. The third edition of the WHO guidelines [200] outlines the procedures to follow and the responsibilities of various organisations and individuals when infectious tuberculosis is diagnosed in a patient who either has a history of recent air travel, or intends to undertake such. The need to evaluate exposed passengers should be assessed when a sputum smear-positive tuberculosis patient is known to have travelled on a flight of $\geqslant 8 \mathrm{~h}$ duration within the preceding three months (D). Where a decision has been taken to evaluate contacts, passengers sitting in the same row and the two rows ahead and behind the index patient should be assessed (D) [199]. The principles outlined in the WHO document summarise the current consensus on how to proceed, and supplement it to assist further adjustment of current guidelines. In particular, the investigation should be limited to instances where there is evidence of transmission from the screening of high priority contacts [201, 247]. Patients with infectious tuberculosis should not normally be allowed to travel on an airplane until they have been certified to be no longer infectious.

\section{Schools}

Contact investigation in schools is often complicated. While the principles of the organisation of contact investigation do not differ from other situations, young classmates or pupils of sputum smear-positive tuberculosis patients will generally be regarded as high- or medium-priority contacts, requiring a lower threshold for widening the investigation. In school outbreaks, transmission of M. tuberculosis can affect a substantial number of contacts [115]. Efforts should be made to conduct the investigation according to the strategies outlined in the previous sections and to prioritise students according to actual degree of exposure (hours shared in the same classroom per week) (C) [115]. Communication of prevention and control procedures to staff, parents and the general public is important to prevent anxiety and unwarranted media attention. Public health authorities should ensure that the media receive and disseminate correct information. If the index case is a pupil and the source of infection unknown, a source investigation as well as a contact investigation may be necessary (C) [248].

\section{Healthcare facilities}

Nosocomial transmission of $M$. tuberculosis is well recognised (B) [16]. Contact investigation is performed when a healthcare worker or in-patient has infectious tuberculosis following a risk assessment in accordance with the principles outlined in the present work (D). Special consideration should be given to the risk of exposure of immunocompromised patients (table 2) and hospital staff, including laboratory staff [249]. In addition, delays in diagnosis and failures in infection control should be taken into account during such risk assessment (D). The healthcare providers and tuberculosis control authorities should agree on who will coordinate the contact investigation and evaluate exposed patient groups and health staff (D).
Vulnerable contacts, as well as their providers, need to be informed on the possibility of exposure and transmission of tuberculosis (D).

In contact investigations in nursing homes for elderly people, screening for latent infection with $M$. tuberculosis and prophylactic treatment with isoniazid are not routinely recommended because of the decreasing risk-benefit ratio with increasing age, unless there are additional risk factors [250, 251].

Recommendations for the management of these groups are: 1) evaluation of symptoms of disease, followed by chest radiography in the individual concerned or among all contacts (D); and 2) education of staff and affected residents thoroughly about symptoms and signs of tuberculosis and the need for immediate medical evaluation if symptoms occur (D).

\section{The homeless and persons living in shelters}

Incidence and prevalence of tuberculosis among the homeless and persons living in shelters is usually high and outbreaks amongst them have been widely recognised in low-incidence countries (C) [252-254]. Overcrowding in shelters for the homeless facilitates transmission. Screening following the diagnosis of a case of tuberculosis should be considered in such a setting. Unfortunately, contact addresses may not always be available (C) [255] and other measures such as mass chest radiography screening for tuberculosis may have to be used (C) [256].

\section{Exposure to animals with $\mathrm{M}$. bovis}

Contact investigation should be limited to those in close contact with an infectious human case due to M. bovis (C) [240], those who have consumed raw milk or unpasteurised dairy products from a cow with tuberculous mastitis [257], and those with regular direct contact with an animal or carcass with pulmonary bovine tuberculosis or lesions of the udder, such as veterinary workers and farmers (D) [258, 259]. The same principles outlined in the management of $M$. tuberculosis exposure should be used.

\section{COMMUNICATION}

Contact investigations will often confront the tuberculosis professional with opposing requests, particularly if the focus of investigation is on congregate settings. To adequately follow the outlined strategy for contact investigation, several days are needed and usually there is no "medical emergency". On the other hand, the anxiety of potential contacts and of their families often requires an "urgent" intervention in the form of correct information and reassurance. In addition, when the media are informed, the timing is reduced to a matter of hours only. This discrepancy is an additional reason why, in any contact investigation, it is important to provide correct information to the contacts and authorities involved as soon as possible. Particularly when contacts in congregate settings or the general public are involved, the timing is important to prevent the spread of incorrect information, in order to reduce the level of anxiety in the community. To reduce the negative impact of misleading and incorrect messages, health authorities should prepare a press release.

Prompt communication to healthcare services and contacts with a low risk of exposure may be helpful in the case of an outbreak, to promote early passive case finding. 


\section{PREREQUISITES}

\section{Health system capacity}

Health systems delivering care and carrying out prevention and control activities are basic components of tuberculosis control. In Europe, they should be able to address the international, national and local challenges in the context of diverse epidemiological situations. The national health authorities involved in tuberculosis control should have a network in place to coordinate the local, regional and national levels, as well as public and private care providers.

The responsibilities of the appropriate public health authorities and healthcare providers at different stages and the components of contact investigations should be clear. However, competing demands restrict the resources that can be allocated to contact investigations. Therefore health authorities have to ensure that resources are allocated to the most cost-effective strategies controlling tuberculosis.

\section{Laboratory services}

The appropriate standards for laboratory services for tuberculosis control programmes in low-incidence countries have been summarised [188]. On top of the required standards for microscopy, nucleic acid amplification, mycobacterial culture and susceptibility testing, standards for DNA fingerprinting techniques need to be agreed upon.

IGRAs offer new opportunities, but many questions remain unanswered. The manufacturers of the ELISPOT suggest that blood can be stored at room temperature for $8 \mathrm{~h}$ before analysis. New test systems that allow an extension of the storage period of blood for the ELISPOT IGRA for $\leqslant 24 \mathrm{~h}$ are advocated by the manufacturer, but clinical data on the performance of these assays are not available yet. The wholeblood ELISA IGRA is technically easier, but when routine phlebotomy services are used, overfilling of the tubes becomes more common $(15 \%$ of samples taken), invalidating the test. Storage at room temperature for $16 \mathrm{~h}$ before incubation is permissible. Thereafter, standards of handling of biological materials apply and are routine in European laboratories.

\section{RESEARCH PRIORITIES AND RECOMMENDATIONS}

Many of the controversies surrounding the usefulness of contact investigation practices are due to the lack of evidence on the (cost-)effectiveness of these interventions and their impact on the tuberculosis epidemic. Indeed, the only randomised controlled trials in this document relate to the efficacy of different preventive therapy regimens for latent infection with $M$. tuberculosis. It is important to realise that the number of patients to treat in order to prevent one tuberculosis case is the reciprocal of the following factors: 1) likelihood of latent infection with $M$. tuberculosis, 2) risk of tuberculosis given infection, 3) efficacy of the regimen, and 4) adherence to treatment [219].

Research should be directed towards answering two practical questions. 1) Who is likely to develop active tuberculosis and should, therefore, recieve preventive therapy? 2) What are the effective preventive therapy regimens and how can adherence to treatment be improved? The first question should preferably be answered before the second. It involves: 1) the relative importance of factors influencing transmission and infection;
2) the need for a test which will most reliably predict which $M$. tuberculosis infected individuals will develop tuberculosis; and 3 ) the cost-effectiveness of contact investigation strategies.

Prospective studies have shown that merely $2 \%$ of those with a positive tuberculin skin test, without concurrent HIV infection, will develop tuberculosis (a frequency that is nevertheless importantly modified by the age of the person) over $2-5$ yrs if left untreated. In this situation, about 70 persons need to be treated to prevent one case of tuberculosis (A) [213]. Children and those with HIV co-infection have higher rates of tuberculosis after contact, but rates in a country with a high incidence of tuberculosis were $10 \%$ and $23 \%$, respectively, after 2 yrs of follow-up [260].

Prior BCG vaccination and the integrity of the cellular immune system at the time of infection is clearly important. Those with concurrent HIV infection are more likely to develop tuberculosis, while those with prior BCG vaccination may benefit from a certain degree of protection.

Data regarding the predictive value of IGRA tests are awaited, but early indications suggest that those who show a T-cell response to the ESAT- 6 and CFP-10 antigens may be more likely to develop tuberculosis (D) [12, 34, 121, 261, 262]. Examination of immune responsiveness in a prospective cohort of household contacts, comparing those who develop tuberculosis with matched controls who did not develop tuberculosis, would be valuable in reducing unnecessary treatment.

Strain characteristics may affect the likelihood of developing tuberculosis. Mycobacterium africanum appears to be less virulent than $M$. tuberculosis, and within the species, the Beijing strain family was associated with an increased risk of tuberculosis subsequent to acquisition of infection [263].

Strain typing, if routinely carried out, can add assurance that tuberculosis in a contact is related to the known index case and not due to reactivation of an earlier-acquired infection from another source.

Short-term studies will only address the problem of early progression to disease. The nature of late reactivation has not been fully elucidated. A long-term register, with a known identity of the initial strain of $M$. tuberculosis, should help in better clarifying the relative contributions of exogenous versus endogenous reinfection disease [264].

Adherence to preventive therapy is frequently poor and regimens are of equally long, if not longer, duration than tuberculosis treatment. There is an urgent need for the development of new drugs against latent infection with $M$. tuberculosis and for clinical trials with shorter regimens, using agents appropriate to the expected low-level metabolic activity of subclinical M. tuberculosis infection. Furthermore, effective preventive therapy regimens for the management of contacts of patients with multidrug-resistant tuberculosis are required.

\section{CONCLUSIONS}

This consensus document provides evidence-based, bestpractice recommendations for the performance of contact investigation among the persons exposed to tuberculosis patients. It stresses the importance of establishing the 


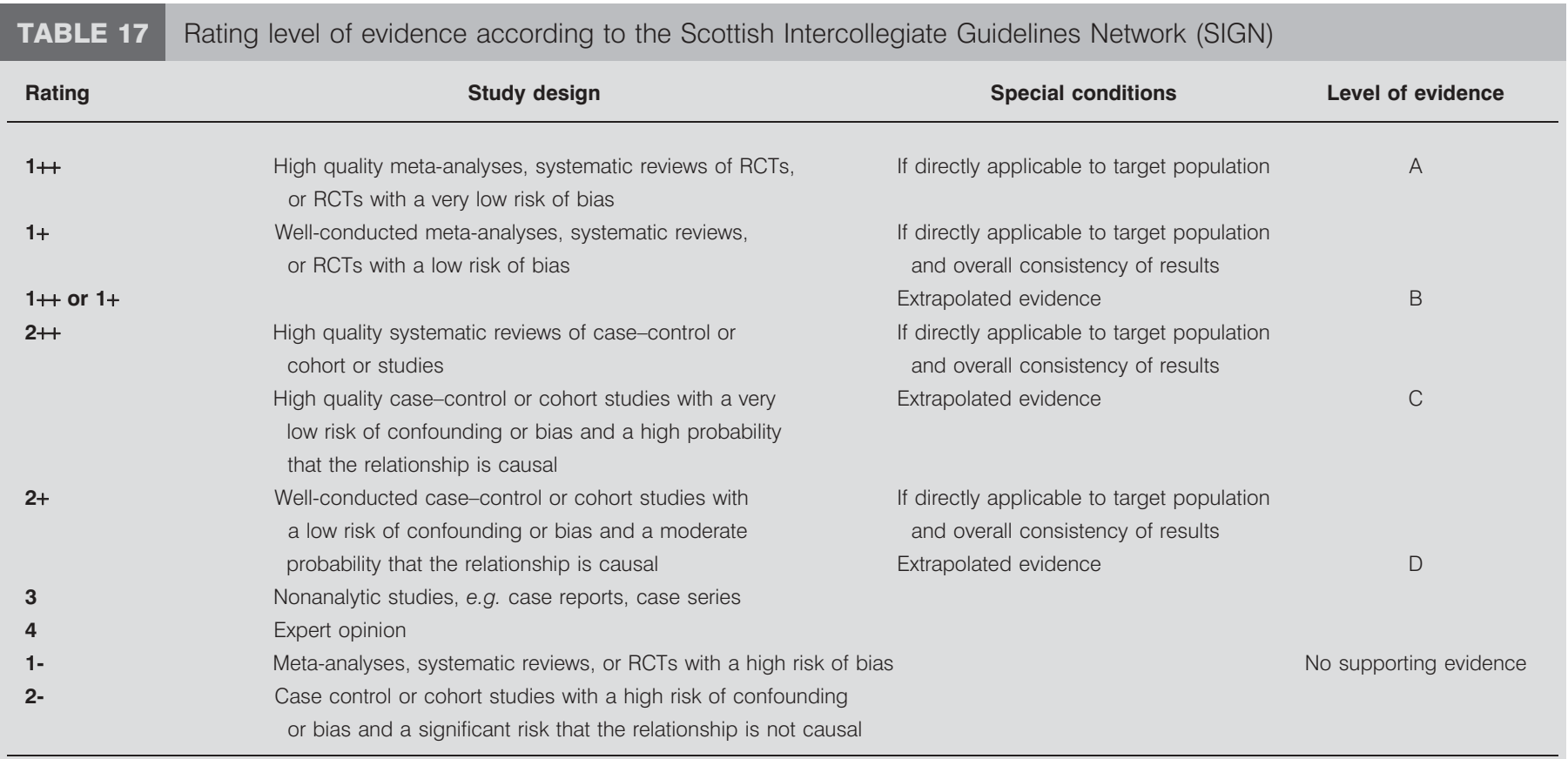

$\mathrm{RCT}$ : randomised controlled trial.

infectiousness of the source case, the likelihood of infection with $M$. tuberculosis among contacts and the risk amongst them to develop tuberculosis, the prioritisation of identified contacts, and the appropriate timing and use of diagnostic tests to diagnose infection with $M$. tuberculosis, and the primordial role in ruling out tuberculosis among identified contacts. Extension of the contact investigation to medium-and low-priority groups should be guided by the evidence of transmission from the source case. Infected contacts should be offered preventive therapy with an effective antimicrobial regimen, balancing risks and benefits of treatment. Outbreaks and the occurrence of tuberculosis cases in communities may necessitate special interventions, but the contact investigation should follow the principle of assessment of exposure risk through evidence of excess transmission to close contacts. Monitoring and evaluation of contact investigation practices will contribute to a better understanding and a more effective use of public resources. Further research must focus on the identification of those contacts with a high risk of developing tuberculosis, diagnostic tests with a high predictive value for the development of active disease, and effective, shorter preventive therapy regimens, including preventive therapy for contacts of patients with multidrug-resistant tuberculosis.

\section{APPENDIX}

For Appendix, see table 17.

\section{STATEMENT OF INTEREST}

Statements of interest for C. Lange and J-P. Zellweger can be found at www.erj.ersjournals.com/misc/statements.dtl

\section{ACKNOWLEDGEMENTS}

The following national correspondents and tuberculosis experts are greatly acknowledged for their input and comments on various versions of the manuscript: D. Antoine (Institut de Veille Sanitaire,
Paris, France), J.A. Caylà (Agència de Salut Pública de Barcelona, Barcelona, Spain), D. Che (Institut de Veille Sanitaire, Paris, France), B. Farrrugia (Chest Clinic, Public Health, Mater Dei Hospital, Malta), B. Hauer (Robert Koch Institute, Berlin, Germany), P. Helbling (Federal Office of Public Health, Bern, Switzerland), S. Keizer (Amsterdam Municipal Health Center, Amsterdam, The Netherlands), V. Kuyvenhoven (KNCV Tuberculosis Foundation, The Hague, The Netherlands), B. Winje (Norwegian Institute of Public Health, Oslo, Norway), E. Rodríguez Valín (National Center for Epidemiology, Carlos III Health Institute, Madrid, Spain), V. Romanus (Swedish Institute for Infectious Disease Control, Solna, Sweden), B. Schmidgruber (Tuberculosis Dept, Public Health Service, Vienna, Austria) and M. Wanlin (Belgian Lung and Tuberculosis Association, Brussels, Belgium).

\section{REFERENCES}

1 World Health Organization. Framework for effective tuberculosis control. http://whqlibdoc.who.int/hq/1994/WHO_TB_94. 179.pdf Date last updated: 1994.

2 Clancy L, Rieder HL, Enarson DA, et al. Tuberculosis elimination in the countries of Europe and other industrialized countries. Eur Respir J 1991; 4: 1288-1295.

3 Tala E, Kochi A. Elimination of tuberculosis from Europe and the world. Eur Respir J 1991; 4: 1159-1160.

4 World Health Organization. An expanded DOTS framework for effective tuberculosis control. Int J Tuberc Lung Dis 2002; 6: 378-388.

5 Raviglione MC, Uplekar MW. WHO's new Stop TB Strategy. Lancet 2006; 367: 952-955.

6 Rieder HL, Zellweger JP, Raviglione MC, et al. Tuberculosis control in Europe and international migration. Eur Respir J 1994; 7: 1545-1553.

7 Rieder HL, Watson JM, Raviglione MC, et al. Surveillance of tuberculosis in Europe. Recommendations of a Working Group of the World Health Organization (WHO) and the European Region of the International Union Against Tuberculosis and 
Lung Disease (IUATLD) for uniform reporting on tuberculosis cases. Eur Respir J 1996; 9: 1097-1104.

8 Veen J, Raviglione M, Rieder HL, et al. Standardized tuberculosis treatment outcome monitoring in Europe. Recommendations of a Working Group of the World Health Organisation (WHO) and the European Region of the International Union Against Tuberculosis and Lung Disease (IUATLD) for uniform reporting by cohort analysis of treatment outcome in tuberculosis patients. Eur Respir J 1998; 12: 505-510.

9 Schwoebel V, Lambregts-van Weezenbeek CSB, Moro ML, et al. Standardization of antituberculosis drug resistance surveillance in Europe. Recommendations of a World Health Organization (WHO) and International Union Against Lung Disease (IUATLD) Working Group. Eur Respir J 2000; 16: 364-371.

10 Broekmans JF, Migliori GB, Rieder HL, et al. European framework for tuberculosis control and elimination in countries with a low incidence. Recommendations of the World Health Organization (WHO), International Union Against Tuberculosis and Lung Disease (IUATLD) and Royal Netherlands Tuberculosis Assoication (KNCV) Working Group. Eur Respir J 2002; 19: 765-775.

11 Drobniewski F, Cobelens F, Zellweger JP. Use of gammainterferon assays in low- and medium prevalence countries in Europe: a consensus statement of a Wolfheze workshop organised by KNCV/EuroTB, Vilnius Sept 2006. Eurosurveillance 2007; 12: 260-257.

12 Bothamley GH, Ditiu L, Migliori GB, et al. Active case finding of tuberculosis in Europe: a Tuberculosis Network European Trials Group (TBNET) survey. Eur Respir J 2008; 32: 1023-1030.

13 European Centre for Disease Prevention and Control. Framework action plan to fight tuberculosis in the European Union. www. ecdc.europea.eu/en/publications/Publications/0803_SPR_TB_ Action_plan.pdf Date last updated: February 2008.

14 World Health Organization Regional Office for Europe. WHO European Ministerial Forum: "All against Tuberculosis". Berlin Declaration on Tuberculosis. www.euro.who.int/ data/assets/ pdf-file/0008/68795/E91369.pdf Date last accessed: 2008.

15 Centers for Disease Control and Prevention. Guidelines for the investigation of contacts of persons with infectious tuberculosis. Recommendations from the National Tuberculosis Controllers Association and CDC. Morb Mortal Wkly Rep 2005; 54: 1-47.

16 The National Collaborating Centre for Chronic Conditions, Tuberculosis. Clinical diagnosis and management of tuberculosis, and measures for its prevention and control. London, Royal College of Physicians, 2006.

17 Public Health Agency Canada. Lung Association Canada. Canadian Thoracic Society. Canadian Tuberculosis Standards. 6th Edn. Ottowa, Public Health Agency of Canada, 2007.

18 Diel R, Forssbohm M, Loytved G, et al. Deutsches Zentralkomittee zur Bekämpfung der Tuberkulose: Empfehlungen für die Umgebungsuntersuchungen bei Tuberkulose [German Central Committee against Tuberculosis: recommendations for environmental contact tracing in tuberculosis]. Pneumologie 2007; 61: 440-455.

19 KNCV Tuberculosis Foundation. Landelijke Coördinatie Infectiektebestrijding. Richtlijn Tuberculosecontactonderzoek. Juni 2007. The Hague, KNCV, 2007.

20 Kaufmann SHE, Cole ST, Mizrahi V, et al. Mycobacterium tuberculosis and the host response. J Exp Med 2005; 201: 1693-1697.

21 Mack U, Migliori GB, Sester M, et al. LTBI: latent tuberculosis infection or lasting immune responses to $M$. tuberculosis? A TBNET consensus statement. Eur Respir J 2009; 33: 956-973.

22 American Thoracic Society, Centers for Disease Control and Prevention. Targeted tuberculin testing and treatment of latent tuberculosis infection. Am J Respir Crit Care Med 2000; 161: S221-S247.
23 Borgen $\mathrm{K}$, Koster B, Meijer H, et al. Evaluation of a large-scale tuberculosis contact investigation in the Netherlands. Eur Respir J 2008; 32: 419-425.

24 Jereb J, Etkind SC, Joglar OT, et al. Tuberculosis contact investigations: outcomes in selected areas of the United States, 1999. Int J Tuberc Lung Dis 2003; 7: Suppl. 3, S384-S390.

25 Poulsen A. Some clinical features of tuberculosis. 1. Incubation period. Acta Tuberc Scand 1954; 24: 311-346.

26 Ferebee SH. Controlled chemoprophylaxis trials in tuberculosis. A general review. Adv Tuberc Res 1969; 17: 28-106.

27 D'Arcy Hart P, Sutherland I. BCG and vole bacillus vaccines in the prevention of tuberculosis in adolescence and early adult life. Final report to the Medical Research Council. BMJ 1977; 2: 293-295.

28 Horsburgh CR Jr. Priorities for the treatment of latent tuberculosis infection in the United States. N Engl J Med 2004; 350: 2060-2067.

29 Marais BJ, Gie RP, Schaaf HS, et al. The natural history of childhood intra-thoracic tuberculosis: a critical review from the pre-chemotherapy era. Int J Tuberc Lung Dis 2004; 8: 392-402.

30 Comstock GW, Livesay VT, Woolpert SF. The prognosis of a positive tuberculin reaction in childhood and adolescence. Am J Epidemiol 1974; 99: 131-138.

31 British Tuberculosis Association. British Tuberculosis Association Annual Conference, 6-9 July 1966. Presentation by Dr I Sutherland. Tubercle 1966; 47: 305-314.

32 Sutherland I. The ten-year incidence of clinical tuberculosis following "conversion" in 2,550 individuals aged 14 to 19 at the time of conversion. Tuberculosis Surveillance Research Unit Progress Report 1968; 1: 61-66.

33 Vynnycky E, Fine PEM. Life time risks, incubation period, and serial interval of tuberculosis. Am J Epidemiol 2000; 152: 247-263.

34 Diel R, Loddenkemper R, Meywald-Walter K, et al. Predictive value of a whole blood IFN- $\gamma$ assay for the development of active tuberculosis diesase after recent infection with Mycobacterium tuberculosis. Am J Respir Crit Care Med 2008; 177: 1164-1170.

35 Driver CR, Cordova IM, Munsiff SS. Targeting tuberculosis testing: the yield of source case investigations for young children with reactive tuberculin skin tests. Public Health Rep 2002; 117: 366-372.

36 Moonan PK, Manruffo M, Manguia-Bayona G, et al. Tuberculosis: what is the yield of associate investigations in non-BCG-immunized children with positive tuberculin skin tests? Int J Tuberc Lung Dis 2005; 9: 322-327.

37 Conde MB, Chindamo Loivos A, Rezende VM, et al. Yield of sputum induction in the diagnosis of pleural tuberculosis. Am J Respir Crit Care Med 2003; 167: 723-725.

38 Hutton MD, Stead WW, Cauthen GM, et al. Nosocomial transmission of tuberculosis associated with a draining abscess. J Infect Dis 1990; 161: 286-295.

39 Templeton GL, Illing LA, Young $\mathrm{L}$, et al. The risk for transmission of Mycobacterium tuberculosis at the bedside and during autopsy. Ann Intern Med 1995; 122: 922-925.

40 Sterling TR, Pope DS, Bishai WR, et al. Transmission of Mycobacterium tuberculosis from a cadaver to an embalmer. $N$ Engl J Med 2000; 342: 246-248.

41 Lauzardo $\mathrm{M}$, Lee $\mathrm{P}$, Duncan $\mathrm{H}$, et al. Transmission of Mycobacterium tuberculosis to a funeral director during routine embalming. Chest 2001; 119: 640-642.

42 Shaw JB, Wynn-Williams N. Infectivity of pulmonary tuberculosis in relation to sputum status. Am Rev Tuberc 1954; 69: 724-732.

43 Grzybowski S, Barnett GD, Styblo K. Contacts of cases of active pulmonary tuberculosis. Tuberculosis Surveillance Research Unit. Report No. 3. Bull Int Union Tuberc 1975; 50: 90-106.

44 van Geuns HA, Meijer J, Styblo K. Results of contact examination in Rotterdam, 1967-1969. Tuberculosis Surveillance Research Unit Report No. 3. Bull Int Union Tuberc 1975; 50: 107-121. 
45 Loudon RG, Roberts RM. Droplet expulsion from the respiratory tract. Am Rev Respir Dis 1966; 95: 435-442.

46 Loudon RG, Roberts RM. Singing and the dissemination of tuberculosis. Am Rev Respir Dis 1968; 98: 297-300.

47 Wells WF. On air-borne infection. Study II. Droplets and droplet nuclei. Am J Hyg 1934; 20: 611-618.

48 Mitchison DA. Drug resistance in mycobacteria. Br Med Bull 1984; 40: 84-90.

49 Toman K. Tuberculosis case-finding and chemotherapy. Questions and answers. Geneva, World Health Organization, 1979.

50 Groothuis DG, Yates MD, eds. Manual of diagnostic and public health mycobacteriology. London, European Society for Mycobacteriology, 1991.

51 Rieder HL, Van Deun A, Kam KM, et al. Priorities for tuberculosis bacteriology services in low-income countries. 2nd Edn. Paris, International Union Against Tuberculosis and Lung Disease, 2007.

52 Urbanczik R, Rieder HL. Scaling up tuberculosis culture services: a precautionary note. (Counterpoint). Int J Tuberc Lung Dis 2009; 13: 801-803.

53 Tostmann A, Kik SV, Kalisvaart NA, et al. Tuberculosis transmission by patients with smear-negative pulmonary tuberculosis in a large cohort in The Netherlands. Clin Infect Dis 2009; 47: 1135-1142.

54 Hertzberg G. The infectiousness of human tuberculosis. An epidemiological investigation. Acta Tuberc Scand 1957; 38: 1-146.

55 Bailey WC, Gerald LB, Kimerling ME, et al. Predictive model to identify positive tuberculosis skin test results during contact investigations. JAMA 2002; 287: 996-1002.

56 Madhi F, Fuhrman C, Monnet I, et al. Transmission of tuberculosis from adults to children in a Paris suburb. Pediatr Pulmonol 2002; 34: 159-163.

57 Loudon RG, Williamson J, Johnson JM. An analysis of 3,485 tuberculosis contacts in the city of Edinburgh during 1954-1955. Am Rev Tuberc Pulm Dis 1958; 77: 623-643.

58 Loudon RG, Spohn SK. Cough frequency and infectivity in patients with pulmonary tuberculosis. Am Rev Respir Dis 1969; 99: 109-111.

59 Devadatta S, Dawson JJY, Fox W, et al. Attack rate of tuberculosis in a 5-year period among close family contacts of tuberculous patients under domiciliary treatment with isoniazid plus PAS or isoniazid alone. Bull World Health Organ 1970; 42: 337-351.

60 Brooks SM, Lassiter NL, Young EC. A pilot study concerning the infection risk of sputum positive tuberculous patients on chemotherapy. Am Rev Respir Dis 1973; 108: 799-804.

61 Gunnels JJ, Bates JH, Swindoll H. Infectivity of sputum-positive tuberculous patients on chemotherapy. Am Rev Respir Dis 1974; 109: 323-330.

62 Jindani A, Doré CJ, Mitchison DA. Bactericidal and sterilizing activities of antituberculosis drugs during the first 14 days. Am J Respir Crit Care Med 2003; 167: 1348-1354.

63 World Health Organization. Tuberculosis infection-control in the era of expanding HIV care and treatment. Addendum to WHO Guidelines for the Prevention of Tuberculosis in Health Care Facilities in Resource-Limited Settings. www.who.int/tb/ publications/tbhu_infectioncontrol_addendum.pdf Date last accessed: August 10, 2010. Date last updated: 2008.

64 Edwards LB, Tolderlund K. BCG-vaccine studies. 3. Preliminary report on the effect of sunlight on BCG vaccine. Bull World Health Organ 1952; 5: 245-248.

65 Edwards LB, Dragsted I. BCG-vaccine studies. 4. Further observations on the effect of light on BCG vaccine. Bull World Health Organ 1952; 5: 333-336.

66 Wells WF, Stone WR. On air-borne infection. Study III. Viability of droplet nuclei infection. Am J Hyg 1934; 20: 619-627.

67 Riley RL. Airborne infection. Am J Med 1974; 57: 466-475.
68 Nardell EA. Catching droplet nuclei. Toward a better understanding of tuberculosis transmission. Am J Respir Crit Care Med 2004; 169: 553-554.

69 Fennelly KP, Martyny JW, Fulton KE, et al. Cough-generated aerosols of Mycobacterium tuberculosis. A new method to study infectiousness. Am J Respir Crit Care Med 2004; 169: 604-609.

70 Rieder HL, Cauthen GM, Comstock GW, et al. Epidemiology of tuberculosis in the United States. Epidemiol Rev 1989; 11: 79-98.

71 Selwyn PA, Hartel D, Lewis VA, et al. A prospective study of the risk of tuberculosis among intravenous drug users with human immunodeficiency virus infection. N Engl J Med 1989; 320: 545-550.

72 Wood R, Maartens G, Lombard CJ. Risk factors for developing tuberculosis in HIV-1-infected adults from communities with a low or very high incidence of tuberculosis. J Acquir Immune Defic Syndr 2000; 23: 75-80.

73 Girardi E, Antonucci G, Ippolito G, et al. Association of tuberculosis risk with the degree of tuberculin reaction in HIVinfected patients. Arch Intern Med 1997; 157: 797-800.

74 Guelar A, Gatell JM, Verdejo J, et al. A prospective study of the risk of tuberculosis among HIV-infected patients. AIDS 1993; 7: 1345-1349.

75 Antonucci G, Girardi E, Raviglione MC, et al. Risk factors for tuberculosis in HIV-infected persons. A prospective cohort study. JAMA 1995; 274: 143-148.

76 Lichtenstein IH, MacGregor RR. Mycobacterial infections in renal transplant recipients: report of five cases and review of the literature. Rev Infect Dis 1983; 5: 216-226.

77 Torre-Cisneros J, Doblas A, Aguado JM, et al. Tuberculosis after solid-organ transplant: incidence, risk factors, and clinical characteristics in RESITRA (Spanish Network of Infection in Transplantation) cohort. Clin Infect Dis 2009; 48: 1657-1665.

78 Körner MM, Hirata N, Tenderich G, et al. Tuberculoiss in heart transplant recipients. Chest 1997; 111: 365-369.

79 Keane J, Gershon S, Wise RP, et al. Tuberculosis associated with infliximab, a tumor necrosis factor a-neutralizing agent. $N$ Engl J Med 2007; 345: 1098-1104.

80 Wolfe F, Michaud K, Anderson J, et al. Tuberculosis infection in patients with rheumatoid arthritis and the effect of infliximab therapy. Arthritis Rheum 2004; 50: 372-379.

81 Tubach F, Salmon D, Ravaud P, et al. Risk of tuberculosis is higher with anti-tumor necrosis factor monoclonal antibody therapy than with soluble tumor necrosis factor receptor therapy. The threeyear prospective French research axed on tolerance of biotherapies registry. Arthritis Rheum 2009; 60: 1884-1894.

82 Kim HA, Yoo CD, Baek HJ, et al. Mycobacterium tuberculosis infection in a corticosteroid-treated rheumatic disease patient population. Clin Experiment Rheumatol 1998; 16: 9-13.

83 Jick SS, Lieberman ES, Rahman MU, et al. Glucocorticoid use, other associated factors, and the risk of tuberculosis. Arthritis Rheum 2006; 55: 19-26.

84 Kaplan MH, Armstrong D, Rosen P. Tuberculosis complicating neoplastic disease. A review of 201 cases. Cancer 1974; 33: 850-858.

85 Feld R, Bodey GP, Gröschel D. Mycobacteriosis in patients with malignant disease. Arch Intern Med 1976; 136: 67-70.

86 Thorn PA, Brookes VS, Waterhouse JAH. Peptic ulcer, partial gastrectomy, and pulmonary tuberculosis. BMJ 1956; 1: 603-608.

87 Steiger Z, Nickel WO, Nedwicki EG, et al. Pulmonary tuberculosis after gastric resection. Am J Surg 1976; 131: 68-671.

88 Pickleman JR, Evans LS, Kane JM, et al. Tuberculosis after jejunoileal bypass. JAMA 1975; 234: 744 .

89 Bruce RM, Wise L. Tuberculosis after jejunoileal bypass for obesity. Ann Intern Med 1977; 87: 574-576.

90 Paul R. Silicosis in northern Rhodesia copper miners. Arch Environ Health 1961; 2: 96-109.

91 Westerholm P, Ahlmark A, Maasing R, et al. Silicosis and risk of lung cancer or lung tuberculosis: a cohort study. Environ Res 1986; 41: 339-350. 
92 Cowie RL. The epidemiology of tuberculosis in gold miners with silicosis. Am J Respir Crit Care Med 1994; 150: 1460-1462.

93 Lundin AP, Adler AJ, Berlyne GM, et al. Tuberculosis in patients undergoing maintenance hemodialysis. Am J Med 1979; 67: 597-602.

94 Chia S, Karim M, Elwood RK, et al. Risk of tuberculosis in dialysis patients: a population-based study. Int J Tuberc Lung Dis 1998; 2: 989-991.

95 Oscarsson PN, Silwer H. Incidence and coincidence of diabetes mellitus and pulmonary tuberculosis in a Swedish county. II. Incidence of pulmonary tuberculosis among diabetics. Search among diabetics in the county of Kristianstad. Acta Med Scand 1958; 161: Suppl. 335, 23-48.

96 Boucot KR, Dillon ES, Cooper DA, et al. Tuberculosis among diabetics. The Philadelphia survey. Am Rev Tuberc 1952; 65: 1-50.

97 Kim SJ, Hong YP, Lew WJ, et al. Incidence of pulmonary tuberculosis among diabetics. Tuber Lung Dis 1995; 76: 529-533.

98 Pablos-Méndez A, Blustein J, Knirsch CA. The role of diabetes mellitus in the higher prevalence of tuberculosis among Hispanics. Am J Public Health 1997; 87: 574-579.

99 Edwards JH. Contribution of cigarette smoking to respiratory disease. Br J Prev Soc Med 1957; 11: 10-21.

100 Gajalakshmi V, Peto R, Santhanakrishna Kanaka T, et al. Smoking and mortality from tuberculosis and other diseases in India: retrospective study of 43000 adult male deaths and 35000 controls. Lancet 2003; 362: 507-515.

101 Lin HH, Ezzati M, Murray M. Tobacco smoke, indoor air pollution and tuberculosis: a systematic review and metaanalysis. PloS Med 2007; 4: e20.

102 Slama K, Chiang CY, Enarson DA, et al. Tobacco and tuberculosis: a qualitative systematic review and meta-analysis. Int J Tuberc Lung Dis 2007; 11: 1049-1061.

103 Pai M, Mohan A, Dheda K, et al. Lethal interaction: the colliding epidemics of tobacco and tuberculosis. Expert Rev Anti-Infect Ther 2007; 5: 385-391.

104 Lönnroth K, Williams BG, Stadlin S, et al. Alcohol use as a risk factor for tuberculosis - a systematic review. BMC Public Health 2008; 8: 289.

105 Rehm J, Samokhalov AV, Neuman MG, et al. The association between alcohol use, alcohol use disorders and tuberculosis (TB). A systematic review. BMC Public Health 2009; 9: 450.

106 Palmer CE, Jablon S, Edwards PQ. Tuberculosis morbidity of young men in relation to tuberculin sensitivity and body build. Am Rev Tuberc Pulm Dis 1957; 76: 517-539.

107 Tverdal A. Body mass index and incidence of tuberculosis. Eur J Respir Dis 1986; 69: 355-362.

108 Maartens G, Wilkinson RJ. Tuberculosis. Lancet 2007; 370: 2030-2043.

109 Lange C, Mori T. Advances in the diagnosis of tuberculosis. Respirology 2010; 15: 220-240.

110 Pai M, Zwerling A, Menzies D. Systematic review: T-cell-based assays for the diagnosis of latent tuberculosis infection: an update. Ann Intern Med 2008; 149: 177-184.

111 Mori $T$. Usefulness of interferon-gamma release assays for diagnosing TB infection and problems with these assays. J Infect Chemother 2009; 15: 143-155.

112 Brock I, Weldingh K, Lillebaek T, et al. Comparison of tuberculin test and new specific blood test in tuberculosis contacts. Am J Respir Crit Care Med 2004; 170: 65-69.

113 Diel R, Ernst M, Döscher G, et al. Avoiding the effect of BCG vaccination in detecting Mycobacterium tuberculosis infection with a blood test. Eur Respir J 2006; 28: 16-23.

114 Diel R, Nienhaus A, Lange C, et al. Tuberculosis contact investigation with a new, specific blood test in a low-incidence population containing a high proportion of BCG-vaccinated persons. Respir Res 2006; 7: 77.

115 Ewer K, Deeks J, Alvarez L, et al. Comparison of T-cell based assay with tuberculin skin test for diagnosis of Mycobacterium tuberculosis infection in a school tuberculosis outbreak. Lancet 2003; 361: 1168-1173.

116 Shams H, Weis S E, Klucar P, et al. Enzyme-linked immunospot and tuberculin skin testing to detect latent tuberculosis infection. Am J Respir Crit Care Med 2005; 172: 1161-1168.

117 Goletti D, Stefania C, Butera O, et al. Accuracy of immunodiagnostic tests for active tuberculosis using single and combined results: a multicenter TBNET-study. PLoS One 2008; e3417.

118 Dosanjh DPS, Hinks TSC, Innes JA, et al. Improved diagnostic evaluation of suspected tuberculosis. Ann Intern Med 2008; 148: 325-336.

119 Kampmann B, Whittaker E, Williams A, et al. Interferon- $\gamma$ release assays do not identify more children with active tuberculosis than the tuberculin skin test. Eur Respir J 2009; 33: 1374-1382.

120 Adetifa IMO, Lugos MD, Hammond A, et al. Comparison of two interferon gamma release assays in the diagnosis of Mycobacterium tuberculosis infection and disease in The Gambia BMC Infect Dis 2007; 7: 122.

121 Hill PC, Jackson-Sillah DJ, Fox A, et al. Incidence of tuberculosis and the predictive value of ELISPOT and Mantoux tests in Gambian case contacts. PLoS One 2008; e1379.

122 Kik SV, Franken WPJ, Mensen M, et al. Predictive value for progression to tuberculosis by IGRA and TST in immigrant contacts. Eur Respir J 2010; 35: 1346-1353.

123 Wasz-Höckert O. On the period of incubation in tuberculosis Ann Med Fenn 1947; 96: 764-772.

124 Wallgren A. The time-table of tuberculosis. Tubercle 1948; 29 245-251.

125 Arnadottir T, Rieder HL, Trébucq A, et al. Guidelines for conducting tuberculin skin test surveys in high prevalence countries. Tuber Lung Dis 1996; 77: Suppl., 1-20.

126 Bouros D, Zervos G, Panaretos C, et al. Palpation versus pen method for the measurement of skin tuberculin reaction (Mantoux test). Chest 1991; 99: 416-419.

127 Rieder HL. Methodological issues in the estimation of the tuberculosis problem from tuberculin surveys. Tuber Lung Dis 1995; 76: 114-121.

128 Comstock GW. False tuberculin test results. Chest 1975; 68: Suppl. 3, 465-469.

129 Guld J, Bentzon MW, Bleiker MA, et al. Standardization of a new batch of Purified Tuberculin (PPD) intended for international use. Bull World Health Organ 1958; 19: 845-951.

130 Comstock GW, Edwards LB, Philip RN, et al. A comparison in the United States of America of two tuberculins, PPD-S and RT 23. Bull World Health Organ 1964; 31: 161-170.

131 Edwards LB, Acquaviva FA, Livesay VT, et al. An atlas of sensitivity to tuberculin, PPD-B, and histoplasmin in the United States. Am Rev Respir Dis 1969; 99: 1-132.

132 Trébucq A, Guérin N, Ali Ismael H, et al. Prevalence and trends of infection with Mycobacterium tuberculosis in Djibouti, testing an alternative method. Int J Tuberc Lung Dis 2005; 9: 1097-1104.

133 Steiner $\mathrm{P}$, Rao M, Victoria MS, et al. Persistently negative tuberculin reactions. Their presence among children with culture positive for Mycobacterium tuberculosis (tuberculin-negative tuberculosis). Am J Dis Child 1980; 134: 747-750.

134 WHO Tuberculosis Research Office. Further studies of geographic variation in naturally acquired tuberculin sensitivity Bull World Health Organ 1955; 22: 63-83.

135 Cobelens FG, Egwaga SM, van Ginkel T, et al. Tuberculin skin testing in patients with HIV infection: limited benefit of reduced cutoff values. Clin Infect Dis 2006; 43: 634-639.

136 Berkel GM, Cobelens FGJ, et al. Tuberculin test: estimation of positive and negative predictive values from routine data. Int $J$ Tuberc Lung Dis 2005; 9: 310-316.

137 Stead WW, To T. The significance of the tuberculin skin test in elderly persons. Ann Intern Med 1987; 107: 837-842. 
138 Mori T, Shiozawa K. Suppression of tuberculin hypersensitivity caused by rubella infection. Am Rev Respir Dis 1985; 131: 886-888.

139 Tamashiro VG, Perez HH, Griffin D. Prospective study of the magnitude and duration of changes in tuberculin reactivity during uncomplicated and complicated measles. Pediatr Infect Dis J 1987; 6: 451-454.

140 Weis Bentzon J. The effect of certain infectious diseases on tuberculin allergy. Tubercle 1953; 34: 34-41.

141 Brody JA, Overfield T, Hammes LM. Depression fo the tuberculin reaction by viral vaccines. $N$ Engl J Med 1964; 271: 1294-1296.

142 Mellman WJ, Wetton R. Depression of the tuberculin reaction by attenuated measles virus vaccine. J Lab Clin Med 1963; 61: 453-458.

143 Wessels G, Hesseling PB, Gie RP, et al. The increased risk of tuberculosis in children with malignancy. Ann Trop Paediatr 1992; 12: $277-281$.

144 Rooney JJ, Crocco JA, Kramer S, et al. Further observations on tuberculin reactions in active tuberculosis. Am J Med 1976; 60: 517-522.

145 Christie LJ, Loeffler AM, Honarmed S, et al. Diagnostic challenges of central nervous system tuberculosis. Emerg Infect Dis 2008; 14: 1473-1475.

146 Smith-Rohrberg D, Sharma SK. Tuberculin skin test among pulmonary sarcoidosis patients with and without tuberculosis: its utility for the screening of the two conditions in tuberculosisendemic regions. Sarcoidosis Vasc Diffuse Lung Dis 2008; 33: 130-134.

147 Pelly TF, Santillan CF, Gilman RH, et al. Tuberculosis skin testing, anergy and protein malnutrition in Peru. Int J Tuberc Lung Dis 2005; 9: 977-984.

148 Baily GV. Tuberculosis Prevention Trial Madras. Indian J Med Res 1980; 72: Suppl., 1-74.

149 Comstock GW. Identification of an effective vaccine against tuberculosis. Am Rev Respir Dis 1988; 138: 479-480.

150 Lalvani A, Bakir M, Millington KA, et al. BCG: protection against infection with Mycobacterium tuberculosis. Int J Tuberc Lung Dis 2006; 10: 826.

151 Neuenschwander BE, Zwahlen M, Kim SJ, et al. Determination of the prevalence of infection with Mycobacterium tuberculosis among persons vaccinated with Bacillus Calmette-Guérin in South Korea. Am J Epidemiol 2002; 155: 654-663.

152 Wang L, Turner MO, Elwood RK, et al. A meta-analysis of the effect of Bacille Calmette Guérin vaccination on tuberculin skin test measurements. Thorax 2002; 57: 804-809.

153 Menzies R, Vissandjee B, Rocher I, et al. The booster effect in twostep tuberculin testing among young adults in Montreal. Ann Intern Med 1994; 120: 190-198.

154 Menzies D. Interpretation of repeated tuberculin tests. Boosting, conversion, and reversion. Am J Respir Crit Care Med 1999; 159: 15-21.

155 Tissot F, Zanetti G, Francioli P, et al. Influence of Bacille Calmette-Guérin vaccination on size of tuberculin skin test reaction: to what size? Clin Infect Dis 2005; 40: 211-217.

156 Stanford JL, Ganapati R, Revankar CR, et al. Sensitization by mycobacteria and the effects of BCG on children attending schools in the slums of Bombay. Tubercle 1988; 69: 293-298.

157 Pinto MRM, Arseculeratne SN, Uragoda CG, et al. Differential tuberculin testing in rural populations in Ceylon. Tubercle 1972; 53: 182-197.

158 Palmer CE, Edwards LB, Hopwood L, et al. Experimental and epidemiologic basis for the interpretation of tuberculin sensitivity. J Pediatr 1969; 55: 413-429.

159 Brooks RW, Parker BC, Gruft H, et al. Epidemiology of infection by nontuberculous mycobacteria. V. Numbers in eastern United States soils and correlation with soil characteristics. Am Rev Respir Dis 1984; 130: 630-633.
160 Reed C, Fordham von Reyn C, Chamblee S, et al. Environmental risk factors for infection with Mycobacterium avium complex. Am J Epidemiol 2006; 164: 32-40.

161 Rust $\mathrm{P}$, Thomas J. A method for estimating the prevalence of tuberculous infection. Am J Epidemiol 1975; 101: 311-322.

162 Griffith DE, Aksamit T, Brown-Elliott BA, et al. An official ATS/ IDSA statement: diagnosis, treatment, and prevention of nontuberculous mycobacterial diseases. Am J Respir Crit Care Med 2007; 175: 367-416.

163 Sørensen AL, Nagai S, Houen G, et al. Purification and characterization of a low-molecular-mass T-cell antigen secreted by Mycobacterium tuberculosis. Infect Immun 1995; 63: 1710-1717.

164 Harboe M, Oettinger T, Wiker HG, et al. Evidence for occurrence of the ESAT-6 protein in Mycobacterium tuberculosis and virulent Mycobacterium bovis and for its absence in Mycobacterium bovis BCG. Infect Immun 1996; 64: 16-22.

165 Pollock JM, Andersen P. The potential of the ESAT-6 antigen secreted by virulent mycobacteria for specific diagnosis of tuberculosis. J Infect Dis 1997; 175: 1251-1254.

166 Berthet FX, Rasmussen PB, Rosenkrands I, et al. A Mycobacterium tuberculosis operon encoding ESAT-6 and a novel low-molecularmass culture filtrate protein (CFP-10). Microbiology 1998; 144: 3195-3203.

167 Gey van Pittius NC, Sampson SL, Lee H, et al. Evolution and expansion of the Mycobacterium tuberculosis PE and PPE multigene families and their association with the duplication of the ESAT-6 (esx) gene cluster regions. BMC Evolut Biol 2006; 6: 95.

168 Vordermeier HM, Brown J, Cockle PJ, et al. Assessment of crossreactivity between Mycobacterium bovis and M. kansasii ESAT-6 and CFP-10 at the T-cell epitope level. Clin Vaccine Immunol 2007; 14: 1203-1209.

169 Arend SM, van Meijgaarden KE, de Boer K, et al. Tuberculin skin testing and in vitro T cell responses to ESAT- 6 and culture filtrate protein 10 after infection with Mycobacterium marinum or $M$. kansasii. J Infect Dis 2002; 186: 1797-1807.

170 Bothamley GH. IFN- $\gamma$-release assays in the management of tuberculosis. Expert Rev Resp Med 2007; 1: 365-375.

171 Brosch R, Gordon SV, Marmiesse M, et al. A new evolutionary scenario for the Mycobacterium tuberculosis complex. Proc Natl Acad Sci 2002; 99: 3684-3689.

172 Beffa P, Zellweger A, Janssens JP, et al. Indeterminate results of $\mathrm{T}^{\mathrm{SPOT}}{ }^{\mathrm{TM}}$.TB performed under routine field conditions. Eur Respir J 2008; 31: 31-842.

173 Rangaka MX, Wilkinson KA, Seldon R, et al. Effect of HIV-1 infection on T-cell-based and skin test detection of tuberculosis infection. Am J Respir Crit Care Med 2007; 175: 514-520.

174 Marais BJ, Pai M. New approaches and emerging technologies in the diagnosis of childhood tuberculosis. Paediatr Respir Rev 2007; 8: 124-133.

175 Stephan C, Wolf T, Goetsch U, et al. Comparing QuantiFERONtuberculosis gold, T-SPOT tuberculosis and tuberculin skin test in HIV-infected individuals from a low prevalence country. AIDS 2008; 22: 2417-2479.

176 Sester U, Junker H, Hodapp T, et al. Improved efficiency in detecting cellular immunity towards $M$. tuberculosis in patients receiving immunosuppressive drug therapy. Nephrol Dial Transplant 2006; 21: 3258-3268.

177 Matulis G, Jüni P, Villiger PM, et al. Detection of latent tuberculosis in immunosuppressed patients with autoimmune diseases: performance of a Mycobacterium tuberculosis antigenspecific interferon $\gamma$ assay. Ann Rheum Dis 2008; 67: 84-90.

178 Sester M, Sester U, Clauer P, et al. Tuberculin skin testing underestimates a high prevalence of latent tuberculosis infection in hemodialysis patients. Kidney Intern 2004; 65: 1826-1834.

179 van Zyl-Smit RN, Pai M, Peprah K, et al. Within-subject variability and boosting of T-cell interferon-g responses after tuberculin testing. Am J Respir Crit Care Med 2009; 180: 49-58. 
180 Leyten EMS, Prins C, Bossink AWJ, et al. Effect of tuberculin skin testing on a Mycobacterium tuberculosis-specific interferon-g assay. Eur Respir J 2007; 29: 1212-1216.

181 van Zyl Smit RN, Zwerling A, Dheda K, et al. Within subject variability of interferon- $\gamma$ assay results for tuberculosis and boosting effect of tuberculin skin testing: a systematic review. PLoS One 2009; 4: e8517.

182 Barnes PF, Verdegem TD, Vachon LA, et al. Chest roentgenogram in pulmonary tuberculosis. New data on an old test. Chest 1988; 94: 316-320.

183 Long R, Maycher B, Scalcini M, et al. The chest roentgenogram in pulmonary tuberculosis patients seropositive for human immunodeficiency virus type 1 . Chest 1991; 99: 123-127.

184 Marciniuk DD, McNab BD, Martin WT, et al. Detection of pulmonary tuberculosis in patients with a normal chest radiograph. Chest 1999; 115: 445-452.

185 Lawn SD, Evans AJ, Sedgwick PM, et al. Pulmonary tuberculosis: radiological features in West Africans coninfected with HIV. $\mathrm{Br} J$ Radiology 1999; 72: 339-344.

186 Mohammed A, Ehrlich R, Wood R, et al. Screening for tuberculosis in adults with advanced HIV infection prior to preventive therapy. Int J Tuberc Lung Dis 2004; 8: 792-795.

187 Bakari M, Arbeit RD, Mtei L, et al. Basis for treatment of tuberculosis among HIV-infected patients in Tanzania: the role of chest X-ray and sputum culture. BMC Infect Dis 2008; 8: 32.

188 Drobniewski FA, Hoffner S, Rusch-Gerdes S, et al. Recommended standards for modern tuberculosis services in Europe. Eur Respir J 2006; 28: 903-909.

189 Conde MB, Soares SLM, Mello FCQ, et al. Comparison of sputum induction with fiberoptic bronchoscopy in the diagnosis of tuberculosis. Experience at an acquired immune deficiency syndrome regerence center in Rio de Janeiro, Brazil. Am Respir Crit Care Med 2000; 162: 2238-2240.

190 Bahammam A, Choudhri S, Long R. The validity of acid-fast smears of gastric aspirates as an indicator of pulmonary tuberculosis. Int J Tuberc Lung Dis 1999; 3: 62-67.

191 Sarmiento OL, Weigle KA, Alexander J, et al. Assessment by meta-analysis of PCR for diagnosis of smear-negative pulmonary tuberculosis. J Clin Microbiol 2003; 41: 3233-3240.

192 Pai M, Kalantri S, Dheda K. New tools and emerging technologies for the diagnosis of tuberculosis: Part II. Active tuberculosis and drug resistance. Expert Rev Mol Diagn 2006; 6: 423-432.

193 Veen J. Microepidemics of tuberculosis: the stone-in-the-pond principle. Tuber Lung Dis 1992; 73: 73-76.

194 Riley RL, Mills CC, O'Grady F, et al. Infectiousness of air from a tuberculosis ward. Ultraviolet irradiation of infected air: comparative infectiousness of different patients. Am Rev Respir Dis 1962; 85: 511-525.

195 Marks SM, Taylor Z, Qualls NL, et al. Outcomes of contact investigations of infectious tuberculosis patients. Am J Respir Crit Care Med 2000; 162: 2033-2038.

196 Behr MA, Hopewell PC, Paz EA, et al. Predictive value of contact investigation for identifying recent transmission of Mycobacterium tuberculosis. Am J Respir Crit Care Med 1998; 158: 465-469.

197 Kenyon TA, Valway SE, Ihle WW, et al. Transmission of multidrug-resistant Mycobacterium tuberculosis during a long airplane flight. N Engl J Med 1996; 334: 933-938.

198 Gerald LB, Tang S, Bruce F, et al. A decision tree for tuberculosis contact investigation. Am J Respir Crit Care Med 2002; 166 $1122-1127$.

199 Driver CR, Valway SE, Morgan WM, et al. Transmission of Mycobacterium tuberculosis associated with air travel. JAMA 1994; 272: 1031-1035.

200 World Health Organization, Tuberculosis and air travel: guidelines for prevention and control. 3rd Edn. www.who.int/tb/
publications/2008/WHO_HTM_2008.399_eng.pdf Date last accessed: August 10, 2010. Date last updated: 2008.

201 European Centre for Disease Prevention and Control, Risk assessment guidelines for diseases transmitted on aircraft. Part 2: Operational guidelines for assisting in the evaluation of risk for transmission by disease. www.ecdc.europa.eu/en/publications/ Publications/0911_GUI_Risk_Assessment_for_Disease

Transmission_on_Aircraft.pdf Date last accessed: August 10, 2010. Date last updated: 2009.

202 Liippo KK, Kulmala K, Tala EOJ. Focusing tuberculosis contact tracing by smear grading of index cases. Am Rev Respir Dis 1993 148: 235-236.

203 Beglinger C, Dudler J, Mottet C, et al. Screening for tuberculosis infection before initiation of anti-TNF- $\alpha$ therapy. Swiss Med Wkly 2007; 137: 621-622.

204 Ormerod LP, Garnett JM. Tuberculin skin reactivity four years after neonatal BCG vaccination. Arch Dis Child 1991; 67: 530-531.

205 Bergamini BM, Losi M, Vaienti F, et al. Performance of commercial blood tests for the diagnosis of latent tuberculosis infection in children and adolescents. Pediatrics 2009; 123: e419-e424.

206 Veerapathran A, Joshi R, Goswami K, et al. T-cell assays for tuberculosis infection: deriving cut-offs for conversions using reproducibility data. PLoS One 2008; e1850.

207 Arend SM, Thijsen SFT, Leyten EMS, et al. Comparison of two interferon-g assays and tuberculin skin test for tracing tuberculosis contacts. Am J Respir Crit Care Med 2007; 175: 618-627.

208 Rieder HL. Estimating the prevalence of tuberculosis infection in the United States population. (Correspondence). Am I Respir Crit Care Med 2008; 178: 651

209 Cook VI, Hernández-Garduño E, Elwood RK. Risk of tuberculosis in screened subjects without known risk factors for active disease. Int J Tuberc Lung Dis 2008; 12: 903-908.

210 Landry J, Menzies D. Preventive chemotherapy. Where has it got us? Where to go next? Int J Tuberc Lung Dis 2008; 12: 1352-1364.

211 International Union Against Tuberculosis Committee on Prophylaxis. Efficacy of various durations of isoniazid preventive therapy for tuberculosis: five years of follow-up in the IUAT trial. Bull World Health Organ 1982; 60: 555-564.

212 Comstock GW. How much isoniazid is needed for prevention of tuberculosis among immunocompetent adults? Int J Tuberc Lung Dis 1999; 3: 847-850.

213 Smieja MJ, Marchetti CA, Cook DJ, et al. Isoniazid for preventing tuberculosis in non-HIV infected persons. Cochrane Database Syst Rev 1999; 1: CD001363.

214 Reichman LB, Lardizabal A, Hayden CH. Considering the role of four months of rifampin in the treatment of latent tuberculosis infection. Am J Respir Crit Care Med 2004; 170: 832-835.

215 Villarino ME, Ridzon R, Weismuller PC, et al. Rifampin preventive therapy for tuberculosis infection. Experience with 157 adolescents. Am J Respir Crit Care Med 1997; 155: 1735-1738.

216 Page KR, Sifakis F, Montes de Oca R, et al. Improved adherence and less toxicity with rifampin vs isoniazid for treatment of latent tuberculosis. A retrospective study. Arch Intern Med 2006; 166: $1863-1870$

217 Hong Kong Chest Service. Tuberculosis Research Centre Madras. British Medical Research Council - A double-blind placebo-controlled clinical trial of three antituberculosis chemoprophylaxis regimens in patients with silicosis in Hong Kong. Am Rev Respir Dis 1992; 145: 36-41.

218 Ena J, Valls V. Short-coure therapy with rifampin plus isoniazid compared with standard therapy with isoniazid, for latent tuberculosis infection: a meta-analysis. Clin Infect Dis 2005; 40 670-677.

219 Rieder HL. Interventions for tuberculosis control and elimination. Paris, International Union Against Tuberculosis and Lung Disease, 2002. 
220 Rennie TW, Bothamley GH, Engova D, et al. Patient choice promotes adherence in preventive treatment for latent tuberculosis. Eur Respir J 2007; 30: 728-735.

221 Meijer J, Barnett GD, Kubik A, et al. Identification of sources of infection. Tuberculosis Surveillance Research Unit Report No. 2. Bull Int Union Tuberc 1971; 45: 5-50.

222 Snider DE Jr, Kelly GD, Cauthen GM, et al. Infection and disease among contacts of tuberculosis cases with drug-resistant and drug-susceptible bacilli. Am Rev Respir Dis 1985; 132: 125-132.

223 Burgos M, DeRiemer K, Small PM, et al. Effect of drug resistance on the generation of secondary cases of tuberculosis. Clin Infect Dis 2003; 188: 1878-1885.

224 Gagneux S, Burgos MV, DeRiemer K, et al. Impact of bacterial genetics on the transmission of isoniazid-resistant Mycobacterium tuberculosis. PLoS Pathogens 2006; 2: e61.

225 Strauss OJ, Warren RM, Jordaan A, et al. Spread of a low-fitness drug-resistant Mycobacterium tuberculosis strain in a setting of high immunodeficiency virus prevalence. J Clin Microbiol 2008; 46: 1514-1516.

226 Fraser A, Paul M, Attamna A, et al. Treatment of latent tuberculosis in persons at risk for multidrug-resistant tuberculosis: systematic review. Int J Tuberc Lung Dis 2006; 10: 19-23.

227 Papastavros T, Dolovich LR, Holbrook A, et al. Adverse events associated with pyrazinamide and levofloxacin in the treatment of latent multidrug-resistant tuberculosis. Can Med Assoc J 2002; 167: 131-136.

228 Younossian AB, Rochat T, Ketterer JP, et al. High hepatotoxicity of pyrazinamide and ethambutol for treatment of latent tuberculosis. Eur Respir J 2005; 26: 462-464.

229 Attamna A, Chemtob D, Attamna S, et al. Risk of tuberculosis in close contacts of patients with multidrug resistant tuberculosis: a nationwide cohort. (Correspondence). Thorax 2009; 64: 271.

230 Seaworth BJ. Multidrug-resistant tuberculosis. Infect Dis Clin N Am 2002; 16: 73-105.

231 World Health Organization, Guidelines for the programmatic management of drug-resistant tuberculosis. Emergency update 2008. http://whqlibdoc.who.int/publications/2008/978924154758 eng.pdf Date last accessed: August 10, 2010. Date last updated: 2008.

232 Wolfheze 2008: tuberculosis management, surveillance and evaluation in Europe with high rates or threat of multidrug resistant tuberculosis. http://www.euro.who.int/_data/assets/ pdf_file/0007/68794/E92047.pdf Date last accessed: 2010. Date last updated: June 2008.

233 Gregg MB. The principles of an epidemic field investigation. In: Holland WW, Detels R, Knox G, eds. Oxford textbook of public health. Oxford, Oxford University Press, 1985: pp. 284-293.

234 Malakmadze N, González I M, Oemig T, et al. Unsuspected recent transmission of tuberculosis among high-risk groups: implications of universal tuberculosis genotyping in its detection. Clin Infect Dis 2005; 40: 366-373.

235 Kik SV, Verver S, van Soolingen D, et al. Tuberculosis outbreaks predicted by characteristics of first patients in a DNA fingerprint cluster. Am J Respir Crit Care Med 2008; 178: 96-104.

236 Allix-Béguec C, Fauville-Dufaux M, Supply P. Three-year population-based evaluation of standardized mycobacterial interspersed repetitive-unit - variable-number tandem-repeat typing of Mycobacterium tuberculosis. J Clin Microbiol 2008; 46: 1398-1406.

237 Wurtz R, Demarais P, Trainor W, et al. Specimen contamination in mycobacteriology laboratory detected by pseudo-outbreak of multidrug-resistant tuberculosis: analysis by routine epidemiology and confirmation by molecular technique. J Clin Microbiol 1996; 34: 1017-1019.

238 Moonan PK, Oppong J, Sahbazian B, et al. What is the outcome of targeted tuberculosis screening based on universal genotyping and location? Am J Respir Crit Care Med 2006; 174: 599-604.
239 Smith RMM, Drobniewski F, Gibson A, et al. Mycobacterium bovis infection, United Kingdom. Emerg Infect Dis 2004; 10: 539-541.

240 Evans JT, Smith EG, Banerjee A, et al. Cluster of human tuberculosis caused by Mycobacterium bovis: evidence for personto-person transmission in the UK. Lancet 2007; 369: 1270-1276.

241 World Health Organization. Tuberculosis control in prisons. A manual for programme managers. www.who.int/tb/publications/ prisons_tb_control_manual/en/index.html Date last accessed: August 10, 2010. Date last updated: 2001.

242 Tuberculosis Coalition for Technical Assistance. International Committee of the Red Cross. Guidelines for control of tuberculosis in prisons. 3rd Edn. The Hague, Tuberculosis Coalition for Technical Assistance, 2009.

243 Seidler A, Nienhaus A, Diel R. Review of epidemiological studies on the occupational risk of tuberculosis in low-incidence areas. Respiration 2005; 72: 431-446.

244 Jochem K, Tannenbaum TN, Menzies D. Prevalence of tuberculin skin test reactions among prison workers. Can J Public Health 1997; 88: 202-206.

245 Centers for Disease Control and Prevention. Prevention and control of tuberculosis in correctional and detention facilities: recommendations from CDC. Endorsed by the Advisory Council for the Elimination of Tuberculosis, the National Commission on Correctional Health Care, and the American Correctional Association. Morb Mortal Wkly Rep 2006; 55: 1-54.

246 Crunch time for tuberculosis control. Lancet 2009; 373: 1145.

247 Abubakar I. Tuberculosis and air travel: a systematic review and analysis of policy. Lancet Infect Dis 2010; 10: 176-183.

248 Paranjothy S, Eisenhut M, Lilley M, et al. Extensive transmission of Mycobacterium tuberculosis from 9 year old child with pulmonary tuberculosis and negative sputum smear. BMJ 2008; 337: 573-575.

249 Menzies D, Joshi R, Pai M. Risk of tuberculosis infection and disease associated with work in health care settings. Int J Tuberc Lung Dis 2007; 11: 593-605.

250 Comstock GW, Edwards PQ. The competing risks of tuberculosis and hepatitis for adult tuberculin reactors. Am Rev Respir Dis 1975; 111: 573-577.

251 Sarasin FP, Perrier A, Rochat T. Isoniazid preventive therapy for pulmonary tuberculosis sequelae: which patients up to which age? Tuber Lung Dis 1995; 76: 394-400.

252 Nava-Aguillera E, Andersson N, Harris E, et al. Risk factors associated with recent transmission of tuberculosis: systematic review and meta-analysis. Int J Tuberc Lung Dis 2009; 13: 17-26.

253 Story A, Murad S, Roberts W, et al. Tuberculosis in London: the importance of homelessness, problem drug use and prison. Thorax 2007; 62: 667-671.

254 Curtis AB, Ridzon R, Novick LF, et al. Analysis of Mycobacterium tuberculosis transmission patters in a homeless shelter outbreak. Int J Tuberc Lung Dis 2000; 4: 308-313.

255 Yun LWH, Reves RR, Reichler MR, et al. Outcomes of contact investigation among homeless persons with infectious tuberculosis. Int J Tuberc Lung Dis 2003; 7: Suppl. 3, S405-S411.

256 de Vries G, van Hest RAH, Richardus JH. Impact of mobile radiographic screening on tuberculosis among drug users and homeless persons. Am J Respir Crit Care Med 2007; 176 201-207.

257 Grange JM. Mycobacterium bovis infection in human beings. Tuberculosis 2001; 81: 71-77.

258 de la Rua-Domenech R. Human Mycobacterium bovis infection in the United Kingdom: incidence, risks, control measures and review of the zoonotic aspects of bovine tuberculosis. Tuberculosis 2006; 86: 77-109.

259 Shrikrishna D, de la Rua-Domenech R, Smith NH, et al. Human and canine pulmonary Mycobacterium bovis infection in the same 
household: re-emergence of an old zoonotic threat? Thorax 2009; 64: 89-91.

260 Guwatudde D, Nakakeeto M, Jones-Lopez EC, et al. Tuberculosis in household contacts of infectious cases in Kampala, Uganda. Am J Epidemiol 2003; 158: 887-898.

261 Doherty TM, Demissie A, Olobo J, et al. Immune responses to the Mycobacterium tuberculosis-specific antigen ESAT-6 signal subclinical infection among contacts of tuberculosis patients. J Clin Microbiol 2002; 40: 704-706.
262 Bakir M, Millington KA, Soysal A, et al. Prognostic value of a Tcell-based, interferon- $\gamma$ biomarker in children with tuberculosis contact. Ann Intern Med 2008; 149: 777-786.

263 de Jong BC, Hill PC, Aiken A, et al. Progression to active tuberculosis, but not transmission, varies by Mycobacterium tuberculosis lineage in The Gambia. J Infect Dis 2008; 198: 1037-1043.

264 Chiang CY, Riley LW. Exogenous reinfection in tuberculosis. Lancet Infect Dis 2005; 5: 629-636. 